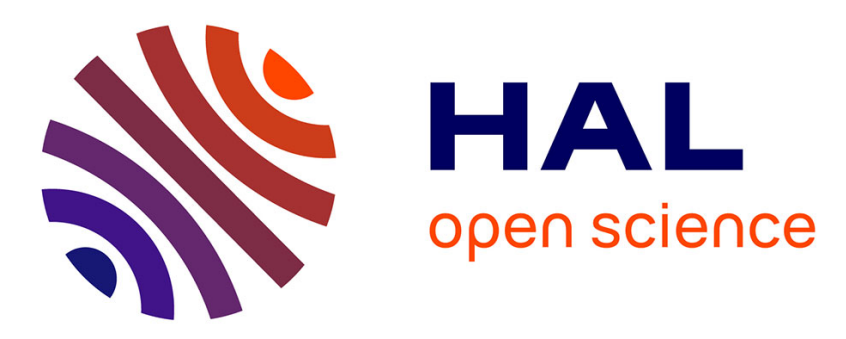

\title{
State-of-the-art review of frost deposition on flat surfaces
}

\author{
Aurélia Léoni, Michèle Mondot, François Durier, Rémi Revellin, Philippe
}

Haberschill

\section{- To cite this version:}

Aurélia Léoni, Michèle Mondot, François Durier, Rémi Revellin, Philippe Haberschill. State-of-the-art review of frost deposition on flat surfaces. International Journal of Refrigeration, 2016, 68, pp.198 217. 10.1016/j.ijrefrig.2016.04.004 . hal-01457281

\section{HAL Id: hal-01457281 https://hal.science/hal-01457281}

Submitted on 6 Feb 2017

HAL is a multi-disciplinary open access archive for the deposit and dissemination of scientific research documents, whether they are published or not. The documents may come from teaching and research institutions in France or abroad, or from public or private research centers.
L'archive ouverte pluridisciplinaire HAL, est destinée au dépôt et à la diffusion de documents scientifiques de niveau recherche, publiés ou non, émanant des établissements d'enseignement et de recherche français ou étrangers, des laboratoires publics ou privés. 


\title{
Review
}

\section{State-of-the-art review of frost deposition on flat surfaces}

\author{
Aurélia Léoni ${ }^{a, b}$, Michèle Mondot ${ }^{b}$, François Durier ${ }^{b}$, Rémi Revellin ${ }^{a, *}$, \\ Philippe Haberschill ${ }^{a}$ \\ a CETHIL UMR5008, Université de Lyon, CNRS, INSA-Lyon, Univ. Lyon 1, F-69621, Villeurbanne, France \\ b Domaine Scientifique de la Doua, Centre Technique des Industries Aérauliques et Thermiques (CETIAT), 25 \\ avenue des Arts, BP 52042, Villeurbanne, 69603, France
}

\section{A R T I C L E I N F O}

Article history:

Received 30 November 2015

Received in revised form 22 March

2016

Accepted 3 April 2016

Available online 12 April 2016

Keywords:

Frost

Density

Thickness

Correlation

Model

\begin{abstract}
A B S T R A C T
This paper presents a comparative study of predictive methods of frost growth and densification on horizontal, vertical and parallel flat surfaces. The study treats two aspects of frost formation: thickness and density. It focuses on the comparison between four different existing theoretical models or empirical correlations and a database gathering almost 382 test points available in the literature for average frost thickness. Furthermore, five correlations are compared to 149 data points for average frost density. Impacts of air velocity, relative humidity and wall temperature are studied. The latter is found to have a significant impact on frost development. Quantitative and qualitative analyses of the predictive methods are proposed. This study leads to the identification of the main issues in the field of modelling of frost deposition on horizontal, vertical and parallel flat plates.
\end{abstract}

(C) 2016 Elsevier Ltd and IIR. All rights reserved.

\section{Synthèse de l'état de l'art du dépôt de givre sur des surfaces planes}

\footnotetext{
* Corresponding author. CETHIL UMR5008, Université de Lyon, CNRS, INSA-Lyon, Univ. Lyon 1, F-69621, Villeurbanne, France. Tel.: +33 4 724372 31; Fax: +33472 438811.

E-mail address: remi.revellin@insa-lyon.fr (R. Revellin). http://dx.doi.org/10.1016/j.ijrefrig.2016.04.004

0140-7007/@ 2016 Elsevier Ltd and IIR. All rights reserved.
} 


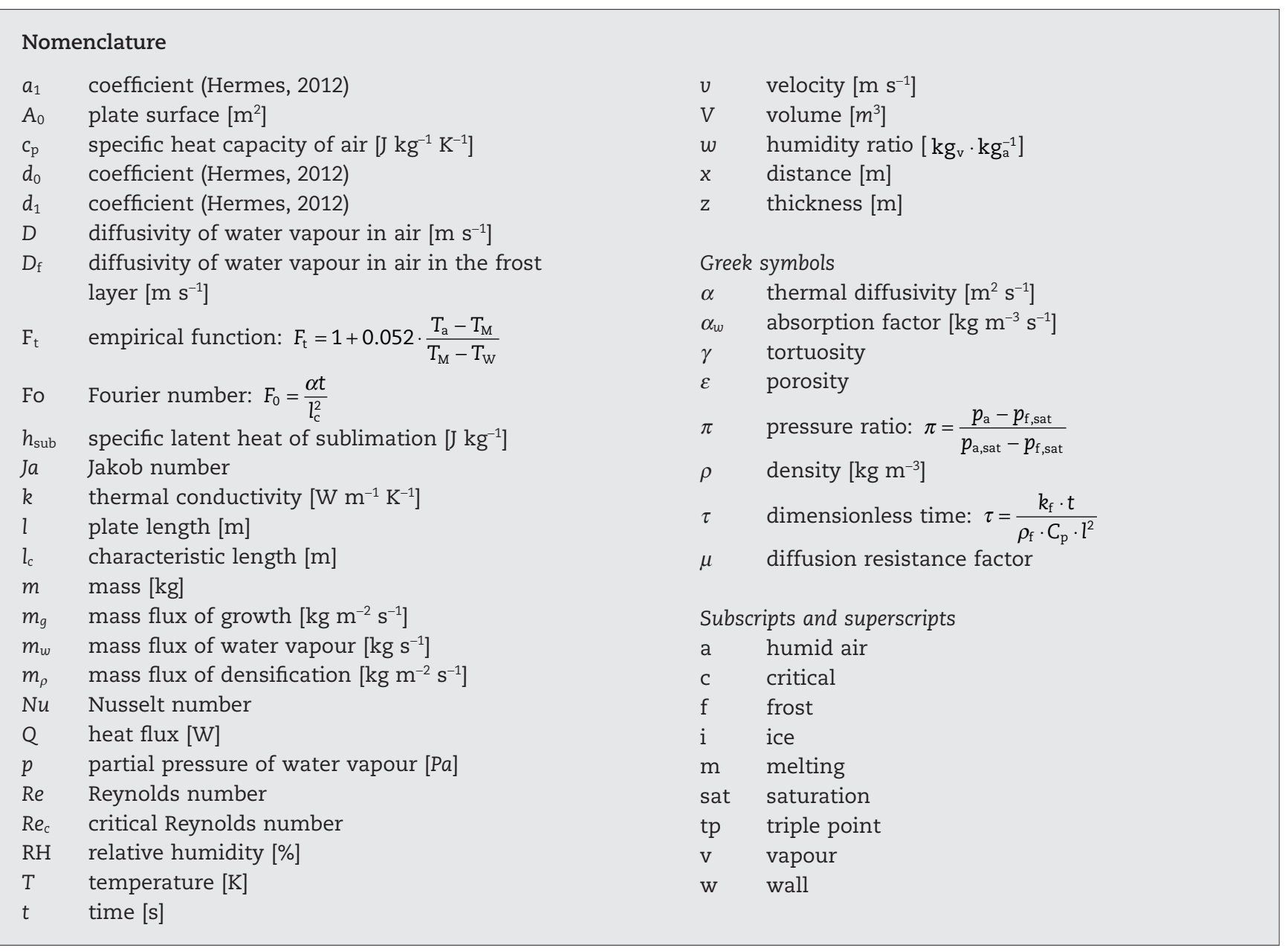

\section{Introduction}

In certain environmental conditions, frost can form and develop on the surface of air refrigeration system evaporator. When surface temperature is below the dew point and above the triple point of water, liquid droplets will condense on the surface. If the dew point is kept positive and the surface temperature is reduced below the triple point, liquid droplets begin to freeze. Frost can also appear by desublimation: water vapour changes directly into frost. Desublimation occurs when surface temperature and dew point are below the triple point of water. The frost layer acts as (i) a thermal insulator between the humid air and the cold surface and (ii) significantly reduces air flow area between the fins of the evaporator, increasing the air pressure drop. Consequently, the energy performance of the system is reduced. A defrosting operation is needed to recover regular performance. This operation is energy consuming and makes the coefficient of performance lower.

In the last decades, lots of surveys investigated frost formation. Hayashi et al. (1977) divided the frost formation process into three steps: (1) the crystal growth period, (2) the frost layer growth period and (3) the frost layer full growth period. This study proposed a first empirical correlation to calculate frost density. Later, Tao et al. (1993) completed this survey, gathering the two last periods. The first stage corresponds to a one- dimensional growth of ice column and the second to a threedimensional growth of the ice column. Hayashi et al. (1977) and Tao et al. (1993) proposed to model the fully developed growth as a homogeneous porous medium in which diffusion leads to the frost growth and densification. Jones and Parker (1975) developed a model based on molecular diffusion of water vapour at the frost interface and using energy and mass balances. Based on the previous model, Sami and Duong (1989) developed a correlation to determine heat transfer coefficient and used Lewis analogy to calculate mass transfer coefficient. Schneider (1978) proposed an empirical correlation for the frost thickness growth. O'Neal and Tree (1984) suggested another frost thickness correlation based on experimental data for parallel plates. Facing the large differences between experimental data and predictions, Lee et al. (1997) developed a model considering a molecular diffusion of watervapour and heat generation due to sublimation from the frost layer, assuming water-vapour in a saturated state at the frost surface. The numerical model was validated with experimental data. Cheng and Cheng (2001) proposed a semi-empirical model considering the Lewis analogy and using the Hayashi et al. (1977) frost density correlation. The theoretical model, compared to the experimental data of Yonko and Sepsy (1967), showed good agreement. Lee et al. (2003) developed a new mathematical model to predict the behaviour of frost layer, without employing any experimental correlation. Compared 
to other models and experimental data, model showed errors of about $10 \%$. This model also allowed obtaining a new correlation for the Lewis number, bounding heat and mass transfer. Wang et al. (2012) developed a generalized model predicting frost growth on flat plates. Concurrently, an experimental bench was constructed in order to validate theoretical results. The authors proposed a new correlation for frost initial density based on the Hayashi et al. (1977) correlation and depending on air temperature, cold surface temperature and frost surface temperature - the Hayashi et al. (1977) correlation was only related to frost surface temperature. Hermes et al. (2009) built a mathematical model based on energy and mass balances, considering frost as a porous medium and the water-vapour in a supersaturated state. The authors also realized experimental tests in order to complete Hayashi et al. (1977) correlation (adding a part related to the cold surface temperature) and to validate the numerical model. In another study, Da Silva et al. (2011) proposed a new frost density correlation depending on frost surface temperature and dew point air temperature. This correlation was used to model frost deposition on fan-supplied tube-fin evaporators. Hermes (2012) completed these studies, proposing an explicit algebraic relationship bounding the frost thickness and the parameters impacting frost formation. In 2015, Nascimento et al. extended this study to frost development on parallel plate channels, proposing a new correlation for frost density and experimental data. Iragorry et al. (2004) proposed a critical review of frost properties and models for frost formation analysis. The authors listed correlations and models available in literature for predicting thermal conductivity, frost density, frost thickness and heat transfer coefficient. All predictive methods are presented with operational ranges and limitations. They identified a lack in the number of studies considering freezer operating conditions with subfreezing air temperatures. The authors suggested that frost surface temperature should be used as an indicating parameter in future defrosting control strategy. Finally, the authors insist on the importance of providing more comparative studies in order to obtain more efficient numerical models.

Further to a deep analysis of bibliography, two parameters are found to be fundamental: frost thickness and frost density.

(a) Frost thickness is an important parameter because it is directly linked to air flow reduction section in air source heat pump technologies. That is why it is essential to identify its impacting parameters (i.e. relative humidity, cold surface temperature,. . .). Experimentally, it is also related to the calculation of the density $\left(\rho=\frac{m}{V}\right)$.

(b) Density is also a fundamental parameter because it has an impact on several other key paramaters such as (Breque and Nemer, 2015):

- the frost porosity as shown in the equation provided by Hermes (2012): $\varepsilon=\frac{\rho_{\mathrm{f}}-\rho_{\mathrm{i}}}{\rho_{\mathrm{a}}-\rho_{\mathrm{i}}}$.

- the frost thermal conductivity. Lots of correlations for frost thermal conductivity can be found in Iragorry et al. (2004) study. Most of the correlations are function of frost density or porosity. The thermal conductivity is used in Fourier's law to calculate temperature of the frost layer: $q=-k_{f} A_{0} \frac{d T}{d x}$.
- the effective diffusivity of water vapour in air in the frost layer $\left(D_{f}=\mu \mathrm{D}\right.$ with $\left.\mu=\frac{\varepsilon}{\gamma}\right)$ which is, in turn, used in Fick's law $\left(m_{\mathrm{w}}=-D_{\mathrm{f}} A_{0} \rho_{\mathrm{a}} \frac{d w}{d x}\right)$.

- the water vapour mass absorption factor: $\frac{d \rho_{\mathrm{f}}}{d \mathrm{t}}=\alpha_{\mathrm{w}}$. This absorption factor is used to quantify the effects of phase change on mass diffusion $\left(\frac{d m_{w}}{d x}=-\alpha_{w} A_{0}\right)$ and heat diffusion $\left(\frac{d q}{d x}=\alpha_{w} A_{0} h_{\text {sub }}\right)$ along the frost layer.

As it can be seen, frost thickness and density are two crucial parameters for solving frosting issues. Lots of correlations and experimental data points are available in the literature. However, studies proposed are isolated. This paper proposes to enhance the very complete study of Iragorry et al. (2004) as suggested by them, with a comparative study of different models and correlations applied to a large number of experimental points found in the literature. This work allows identifying the main issues from the current available literature.

\section{Experimental data from the literature}

\subsection{Database presentation}

Data points available in the literature were gathered in two databases focusing on frost thickness growth and densification, respectively, on horizontal flat plates. The thickness database combines each frost thickness data point along with their underlying experimental parameters such as: air temperature, wall temperature (cold source), relative humidity, air velocity, time and plate length (the plate length needs to be known for some models). Data points collected are averaged values (thickness and density are considered uniform along the plate length). Each data point can be used in different models and correlations available in the literature. The number of data points for frost thickness is 382. Database for frost density considers all previous parameters and also frost surface temperature when it was given by the authors (some correlations need frost surface temperature).

Sources of experimental data and ranges of operational parameters are presented in Table 1 for frost thickness and in Table 2 for frost density.

Lee et al.'s (2003) experimental data points were not taken into account because they seemed to be incorrect. Indeed, there was no consistency between these data and all predictive methods. To be careful, authors of the present study preferred not taking into account these experimental data.

The first scope of this work is to identify the consequences of the operational parameters on frost thickness and density development.

\subsection{Impact of environmental parameters}

\subsubsection{Frost thickness}

The influence of wall surface temperature on frost thickness formation is shown in Fig. 1a. Other parameters are kept 
Table 1 - Range of values of author's thickness database.

\begin{tabular}{|c|c|c|c|c|c|c|}
\hline \multicolumn{3}{|c|}{ Experimental data source } & \multicolumn{4}{|c|}{ Range of values } \\
\hline Authors & Symbol & $\begin{array}{l}\text { Number of } \\
\text { points }\end{array}$ & $\begin{array}{l}\text { Air temperature } \\
\qquad\left[{ }^{\circ} \mathrm{C}\right]\end{array}$ & Wall temperature $\left[{ }^{\circ} \mathrm{C}\right]$ & $\begin{array}{c}\text { Relative } \\
\text { humidity [\%] }\end{array}$ & $\begin{array}{l}\text { Air velocity } \\
{\left[\mathrm{m} \cdot \mathrm{s}^{-1}\right]}\end{array}$ \\
\hline $\begin{array}{l}\text { Yonko and Sepsy } \\
\text { (1967) }\end{array}$ & * & 74 & {$[21 ; 23]$} & {$[-28 ;-8]$} & {$[57 ; 80]$} & {$[0.27 ; 2.96]$} \\
\hline $\begin{array}{l}\text { Jones and Parker } \\
\qquad(1975)\end{array}$ & $\bullet$ & 21 & {$[22 ; 25]$} & {$[-30 ;-8]$} & {$[38 ; 26]$} & {$[1.19 ; 2.96]$} \\
\hline Lee et al. (1997) & $\nabla$ & 40 & 25 & -15 & {$[50 ; 80]$} & {$[0.18 ; 5.00]$} \\
\hline Lee et al. (2003) & $<$ & 21 & {$[5 ; 15]$} & {$[-20 ;-15]$} & {$[60 ; 70]$} & {$[1.0 ; 2.5]$} \\
\hline Hermes et al. (2009) & $\Delta$ & 125 & {$[16 ; 22]$} & {$[-16 ;-4]$} & {$[50 ; 80]$} & {$[0.7 ; 1.0]$} \\
\hline Cai et al. (2011) & + & 6 & 15 & -10 & 65 & 0.25 \\
\hline Wang et al. (2012) & 0 & 90 & {$[-8 ; 19]$} & {$[-16 ;-8]$} & {$[42 ; 80]$} & {$[2.22 ; 5.00]$} \\
\hline Kandula (2014) & $\times$ & 5 & 22.1 & -9.1 & 72 & 1.77 \\
\hline \multicolumn{2}{|l|}{ Total } & 382 & {$[-8 ; 25]$} & {$[-30 ;-4]$} & {$[38 ; 80]$} & {$[0.18 ; 5.00]$} \\
\hline
\end{tabular}

constant. Experimental data provided by Hermes (2012) show that the lower the surface temperature, the thicker the frost layer. It can be concluded that cold surface temperature has a significant impact on frost growth. This tendency was confirmed with all the points available in the database.

Impact of air velocity is illustrated in Fig. 1b. Experimental data provided are from Lee et al. (1997) and Hermes (2012). In their experiments, conditions remain constant, except for velocity values. Fig. $1 \mathrm{~b}$ shows that frost thickness increases with velocity for Lee et al.'s (1997) results. However, Hermes et al.'s (2009) results do not show any significant difference, maybe due to the small velocity difference. Generally speaking, a higher air velocity means a higher quantity of water vapour freezing probably because of higher heat and mass transfer coefficients.

The influence of relative humidity is studied, thanks to Lee et al.'s (1997) experimental data. Frost thickness is given for relative humidity of $50 \%, 70 \%$ and $80 \%$. Other experimental conditions are kept constant. Fig. 1c shows that frost thickness increases with relative humidity. This influence is easily understandable because, at the same air temperature, a higher relative humidity means higher quantity of water in the air.
When the air is in contact with the cold surface, higher quantity of water vapour freezes on the plate surface. For high relative humidity, frost velocity growth is found to be more important at the beginning of the tests.

\subsubsection{Frost density}

Fig. 2 shows frost density evolution for several varying parameters. As for frost thickness, when the impact of one parameter is studied, others are kept constant. Results are given for different wall temperatures, air velocities and relative humidity. Fig. 2a shows the impact of wall temperature. It can be observed that frost density decreases with low temperatures. It means that high temperatures encourage densification of the frost layer: mass flux contributing to the frost layer mass rise is higher than mass flux leading to thickness augmentation. This observation agrees with observations of the wall temperature impact on frost thickness. For air velocities, conclusion is the same as for frost thickness: density increases with high velocities. Reynolds number increase leads to a denser frost layer. Heat and mass transfers are locally boosted, leaving less space to the air in the porous layer. For the impact of relative humidity, conclusions are not clear. Indeed, results obtained

Table 2 - Range of values of author's density database.

\begin{tabular}{|c|c|c|c|c|c|c|}
\hline \multicolumn{3}{|c|}{ Experimental data } & \multicolumn{4}{|c|}{ Range of values } \\
\hline Authors & Symbol & $\begin{array}{l}\text { Number of } \\
\text { points }\end{array}$ & $\begin{array}{c}\text { Air temperature } \\
{\left[{ }^{\circ} \mathrm{C}\right]}\end{array}$ & Wall temperature $\left[{ }^{\circ} \mathrm{C}\right]$ & $\begin{array}{c}\text { Relative } \\
\text { humidity [\%] }\end{array}$ & $\begin{array}{c}\text { Air velocity } \\
{\left[\mathrm{m} \cdot \mathrm{s}^{-1}\right]}\end{array}$ \\
\hline Hayashi et al. (1977) & * & 58 & 25 & {$[-18.6 ;-5.1]$} & 38 & {$[2 ; 6]$} \\
\hline Lee et al. (2003) & $\begin{array}{c}\text { Not taken } \\
\text { into account }\end{array}$ & 21 & {$[5 ; 15]$} & {$[-20 ;-15]$} & {$[60 ; 70]$} & {$[1.0 ; 2.5]$} \\
\hline Shin et al. (2003) & * & 4 & 12 & -22 & {$[38 ; 80]$} & {$[0.7 ; 6.0]$} \\
\hline Hermes et al. (2009) & $\Delta$ & 52 & {$[16 ; 22]$} & {$[-16 ;-4]$} & {$[50 ; 80]$} & 0.7 \\
\hline Wang et al. (2012) & $\diamond$ & 15 & {$[-8 ; 19]$} & {$[-16 ;-8]$} & {$[12 ; 80]$} & 5 \\
\hline Kandula (2014) & $\circ$ & 3 & 22.1 & -9.3 & 71.6 & 1.77 \\
\hline \multicolumn{2}{|l|}{ Total } & 149 & {$[-8 ; 25]$} & {$[-22 ;-4]$} & {$[12 ; 80]$} & {$[0.7 ; 6.0]$} \\
\hline
\end{tabular}




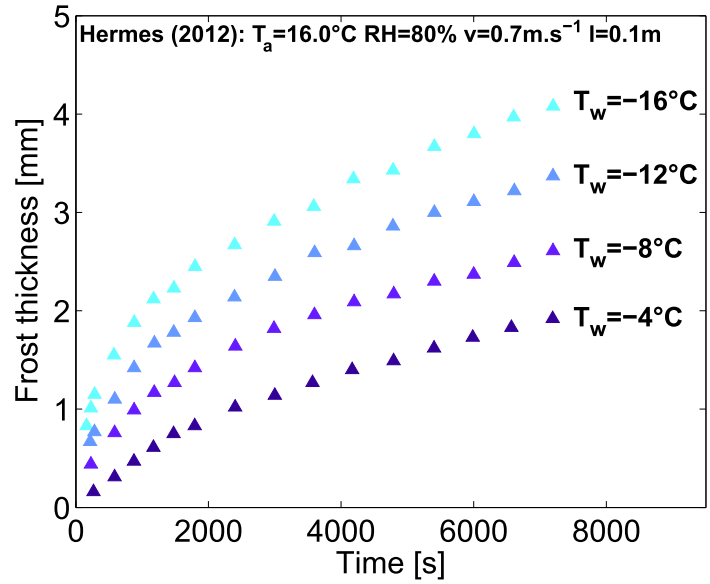

(a) Wall temperature

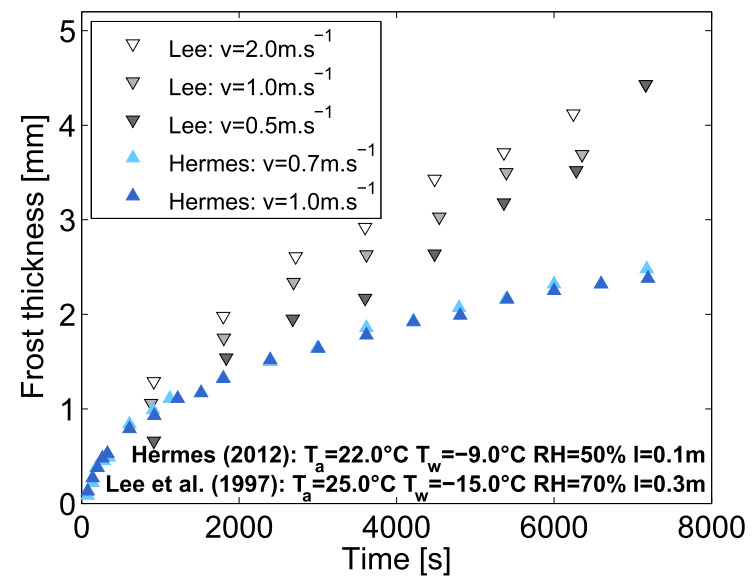

(b) Air velocity

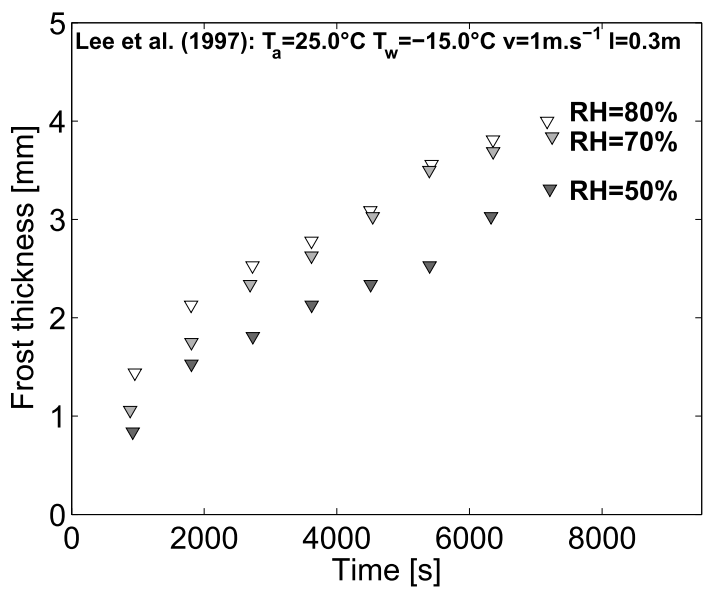

(c) Relative humidity

Fig. 1 - Impact of environmental parameters on frost thickness.

for the two authors are not in agreement. In their work, Hermes et al. (2009) observed that frost layer was denser with high relative humidity, but Wang et al.'s (2012) experimental data show that density was higher for medium relative humidity. As the frost density phenomenon is not as intuitive as frost thickness formation, it is not possible to bring strong conclusions. Density depends not only on the frost mass deposed but also on the thickness of the frost layer: predominance of one of the two factors has to be clarified.

This parametric study on experimental data available in the literature shows that frost formation phenomenon is not well understood. More particularly concerning density, more experimental tests are needed to understand the impact of different parameters. Attention should be focused on relative humidity.

\section{Existing predictive methods}

A lot of studies regarding the treatment of frost formation, more particularly on thickness and density paremeters, can be found in the literature. These studies are various according to the ge- ometry studied (flat plates, cylinders, fin-tube evaporators, .. .) and the type of the study (experimental, analytical, numerical,. . .). Most of the studies treat the global formation of frost. However, several studies focusing on local development of frost crystals can be found in the literature. In fact, in 1968, Fukuta (1968) studied growth rates of ice crystals. Results were found different according to the cold surface temperature, which was explained by the crystal shapes. Wu et al. (2007) associated crystal shapes to range of cold surface temperatures. Five different shapes were observed and classified. Different models focusing on local formation of frost crystals were proposed by Le Gall and Griot (1997) and Na and Webb (2004). They allowed taking into account crystal structures in the equations. These are completed with studies from Seki et al. (1985) and Piucco et al. (2008). The authors propose frost nucleation models. New parameters as contact angle or radius of embryo are taken into account. These condiserations led to more precision in modelling. These models are also more complex and difficult to study and compare because they require data that are not provided in most publications (contact angle of the freezing surface, embryo characteristics). That is why they will not be studied in this paper. Nevertheless, these kinds of studies are 


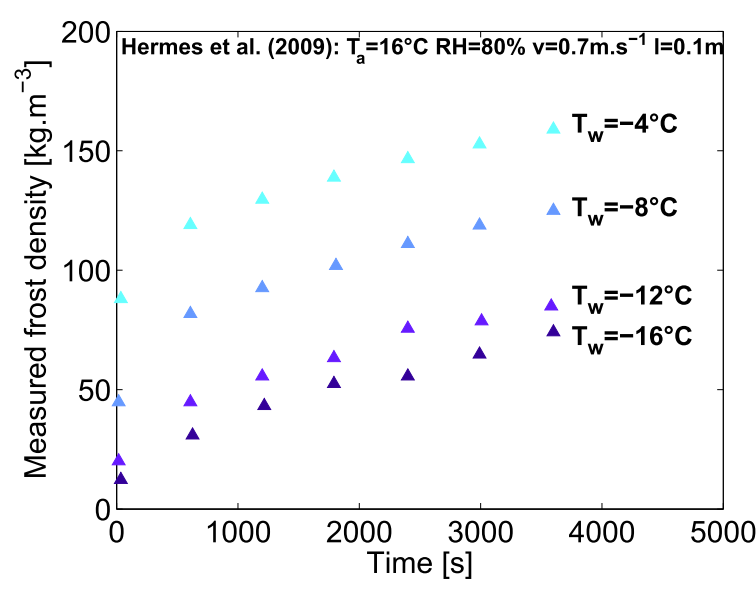

(a) Wall temperature

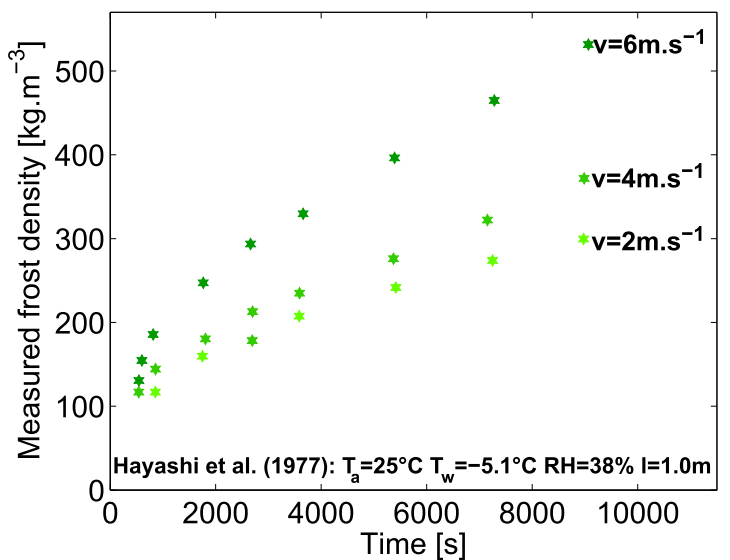

(b) Air velocity

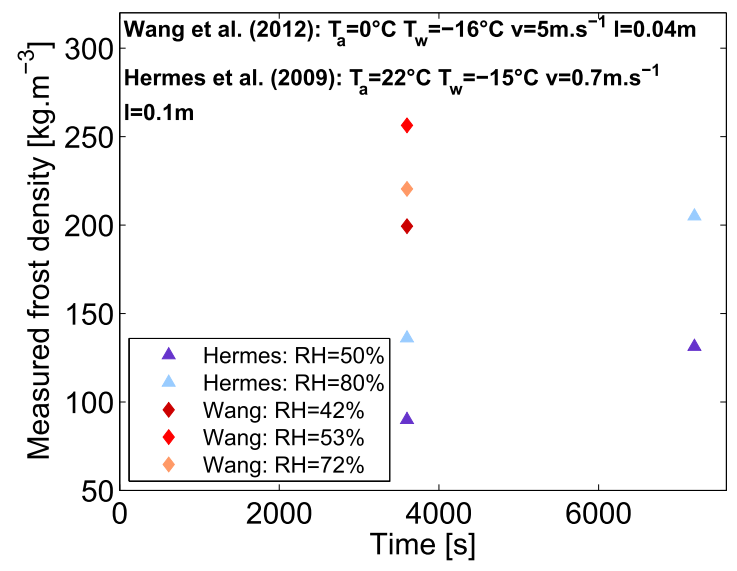

(c) Relative humidity

Fig. 2 - Impact of environmental parameters on frost density.

essential to understand the basis in the field of frost formation. In this study, the authors are focusing on correlations and simple models predicting frost formation on flat plates.

\subsection{Presentation of the predictive methods}

\subsubsection{Correlation and models for frost thickness}

Four predictive time-dependent methods for the frost thickness formation over time are evaluated in this study. Among these predictive methods, one is an empirical correlation and three are theoretical models. The first relation used to describe frost thickness is the Schneider (1978) correlation. This correlation was realized, thanks to data points experimentally obtained on a tube. Authors precise that the frost thickness was independent of the position along the circumference of the tube. That is why the authors of the present study chose to test this correlation.

$$
\begin{aligned}
\mathrm{z}_{\text {Schneider }}= & 0.465 \cdot\left(\frac{k_{\mathrm{i}}}{h_{\text {sub }} \rho_{\mathrm{i}}} \cdot\left(\mathrm{T}_{\mathrm{f}}-\mathrm{T}_{\mathrm{w}}\right)\right)^{0.5} \cdot\left(\frac{\mathrm{t}}{1 \mathrm{~h}}\right)^{-0.03}\left(\frac{\mathrm{T}_{\mathrm{f}}-\mathrm{T}_{\mathrm{m}}}{1 \mathrm{~K}}\right)^{0.01} \\
& \times\left(\frac{p-p_{\mathrm{f}, \text { sat }}}{p_{\text {sat }}-p_{\mathrm{f}, \mathrm{sat}}}\right)^{0.25} \cdot \mathrm{F}_{\mathrm{t}}
\end{aligned}
$$

where $1 \mathrm{~h}$ represents one hour and $1 \mathrm{~K}$ represents one Kelvin. These two constants were probably used to obtain nondimensional parameters. $F_{t}$ is defined by the next equation:

$F_{t}=1+0.052 \cdot \frac{T_{f}-T_{m}}{T_{m}-T_{w}}$

$p, p_{\text {sat }}$ and $p_{\mathrm{f}, \mathrm{sat}}$ represent, respectively, partial pressure of water vapour, saturation pressure of vapour in moist air and saturation pressure of vapour at frost surface temperature.

This correlation is time-dependent and depends on operational parameters such as wall temperature and water vapour quantity in air. It can be noted that frost thickness is square root dependent on the time that traduces diffusive dominant mass transfer (Hermes, 2012 and Storey and Jacobi, 1999). The weakness of this correlation lies in the fact that it cannot be applied to all experimental conditions. In fact, tests with high air temperature combined with low relative humidity cannot be simulated with this correlation because of the pressure ratio. Some environmental condition makes it negative, leading to complex form of numerical results.

The three theoretical models are those of Lee et al. (1997), Hermes et al. (2009) and Hermes (2012). To complete the study, 


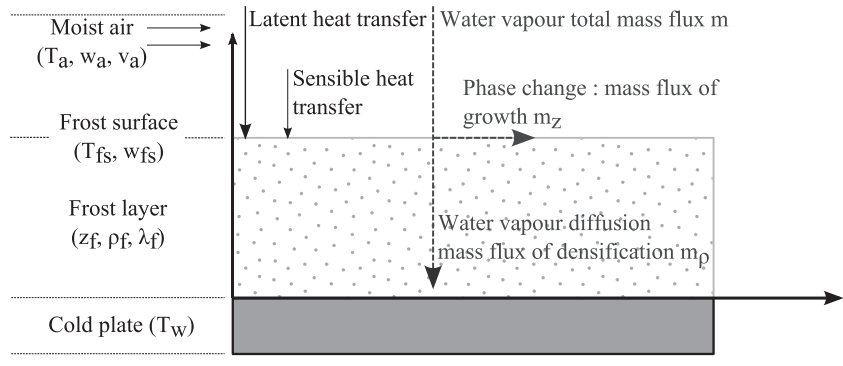

Fig. 3 - Physical model for frost development on flat plate.

the model of Wang et al. (2012) was also reproduced but without satisfactory results. As a matter of fact, the explanations provided by the authors in their paper did not allow us to obtain the same results as theirs. As a consequence, the Wang et al. (2012) model was not taken into account.

In their models, Lee et al. (1997) and Hermes et al. (2009) assume that total mass flow rate of vapour contributes to frost density and frost thickness augmentation as illustrated in Fig. 3. Frost thickness is defined as:

$\left.z_{\mathrm{f}}\right|_{t+\Delta t}=\left.z_{f}\right|_{t}+\left.\Delta t \cdot \frac{m_{z}}{\rho_{\mathrm{f}}}\right|_{\mathrm{t}}$

The two models differ in the frost density calculation. Hermes et al. (2009) calculate frost density at each time step with an empirical correlation. On the contrary, Lee et al. (1997) consider frost density as a function of mass flux of densification. The Hermes et al. (2009) model requires initial frost thickness, which was set at $1.0 \mu \mathrm{m}$. The Lee et al. (1997) model requires initial frost thickness and density. Both values are not provided by the authors. However, analysis of their tests showed that an initial frost thickness of $0.1 \mu \mathrm{m}$ and an initial frost density of $47 \mathrm{~kg} \mathrm{~m}^{-3}$ can be assumed. However, it should be kept in mind that this choice can cause some imprecision when applying it to the whole database.

These two previous models are integrated analytically and need numerical integration of one time dependent ordinary differential equation. Hermes (2012) simplified his previous model by proposing an analytical relationship between frost thickness, time and influential parameters. The author defined frost thickness as:

$\mathrm{Z}_{\mathrm{f}}=l \cdot \frac{\sqrt{d_{1}^{2}+4 d_{0} \cdot \tau}-d_{1}}{2}$

with $d_{1}$ and $d_{0}$ as functions of air temperature, wall temperature, humidity ratio and air velocity.

Two pioneer correlations from Mao et al. (1992) and Mao et al. (1999) are not tested in this study. The reason is that these correlations need the knowledge of the dimensionless position ratio. This ratio depends on the position along the plate, so thickness has to be known for each abscissa $a$. As frost thickness values are averaged values, these correlations cannot be implemented.

Table 3 gathers predictive methods for frost thickness presented above and their range of application.

\begin{tabular}{|c|c|}
\hline Predictive method & Range of application \\
\hline Hermes et al. (2009) & $\begin{array}{l}-16 \leq T_{\mathrm{w}} \leq-4^{\circ} \mathrm{C} \\
16 \leq \mathrm{T}_{\mathrm{a}} \leq 22^{\circ} \mathrm{C} \\
50 \leq \mathrm{RH} \leq 80 \% \\
6000 \leq \mathrm{Re} \leq 50000 \\
50 \leq \rho_{\mathrm{f}} \leq 400 \mathrm{~kg} \cdot \mathrm{m}^{-3} \\
0 \leq \mathrm{t} \leq 120 \mathrm{~min}\end{array}$ \\
\hline Lee et al. (1997) & $\begin{array}{l}\mathrm{T}_{\mathrm{w}}=-15^{\circ} \mathrm{C} \\
\mathrm{T}_{\mathrm{a}}=25^{\circ} \mathrm{C} \\
50 \leq \mathrm{RH} \leq 80 \% \\
6000 \leq \operatorname{Re} \leq 50000 \\
50 \leq \rho_{\mathrm{f}} \leq 400 \mathrm{~kg} \cdot \mathrm{m}^{-3} \\
0 \leq \mathrm{t} \leq 120 \mathrm{~min}\end{array}$ \\
\hline Schneider (1978) & $\begin{array}{l}-30 \leq T_{\mathrm{w}} \leq-5^{\circ} \mathrm{C} \\
5 \leq \mathrm{T}_{\mathrm{a}} \leq 15^{\circ} \mathrm{C} \\
96 \leq \mathrm{RH} \leq 99 \% \\
4000 \leq \operatorname{Re} \leq 32000 \\
60 \leq \mathrm{t} \leq 480 \mathrm{~min}\end{array}$ \\
\hline Hermes (2012) & $\begin{array}{l}5.3 \leq a_{1} \cdot\left(T_{\mathrm{a}}-\mathrm{T}_{\mathrm{w}}\right) \leq 8.5^{\circ} \mathrm{C} \\
0.0057 \leq w_{\mathrm{a}}-w_{\mathrm{w}} \leq 0.0090 \mathrm{~kg}_{\mathrm{v}} \cdot \mathrm{kg}^{-1} \\
\operatorname{Re} \leq 3 \cdot 10^{7} \\
29.3 \leq \mathrm{Nu} \leq 40.6 \\
82 \leq \rho_{\mathrm{f}} \leq 318 \mathrm{~kg} \cdot \mathrm{m}^{-3} \\
0 \leq \mathrm{t} \leq 120 \mathrm{~min}\end{array}$ \\
\hline
\end{tabular}

\subsubsection{Correlations for frost density}

Four empirical correlations are used to predict frost density over time. The first relation used to evaluate frost density is given by Hayashi et al. (1977) (Eq. 5). This relation only depends on frost surface temperature.

$\rho_{\mathrm{fHayashi}_{\mathrm{H}}}=650 \cdot \exp \left(0.277 \cdot \mathrm{T}_{\mathrm{f}}-273.15\right)$

Kandula (2012) proposed a new correlation more completely, taking account of the wall temperature and the air velocity (Eq. 6).

$$
\begin{aligned}
\rho_{\text {fKandula }}= & \rho_{\mathrm{i}} \cdot\left[0 . 5 \cdot ( \frac { \mathrm { T } _ { f } - \mathrm { T } _ { \mathrm { w } } } { \mathrm { T } _ { m } - \mathrm { T } _ { \mathrm { w } } } ) \cdot \operatorname { e x p } \left(-\left(0.376+1.5 \cdot\left(\frac{\mathrm{T}_{\mathrm{f}}-\mathrm{T}_{\mathrm{w}}}{\mathrm{T}_{\mathrm{m}}-\mathrm{T}_{\mathrm{w}}}\right)\right)\right.\right. \\
& \left.\left.\times\left(1-\sqrt{\frac{R e}{R e_{\mathrm{c}}}}\right)\right)\right]
\end{aligned}
$$

with $\rho_{\mathrm{i}}$ as the frost density of ice.

Kandula (2012) considered that taking account of the frost surface temperature in the frost density calculation allows better predictions. But, in the present study, the two previous correlations are considered restrictive. In fact, the frost temperature is not an input in the frost formation phenomenon. The use of these correlations requires the knowledge of the frost surface temperature. However, none of the authors provide a way to determine this temperature. So, these correlations can only be applied when frost surface temperature is known, which represents a small part of the studies. To bypass this weakness, the authors of the present study chose to determine frost surface temperature with the model of Hermes et al. (2009) used in the thickness section, and applied to the density database.

Hosoda and Uzuhashi (1967) proposed a correlation based on wall temperature and air velocity. Equation 7 shows the relation. 
$\rho_{\mathrm{fHosoda}}=340\left|\mathrm{~T}_{\mathrm{w}}\right|^{-0.445}+85 \cdot v_{\mathrm{a}}$

$\mathrm{T}_{w}$ must be used in this correlation in Celsius degree.

Yang and Lee (2004) developed a correlation based on dimensionless numbers:

$\rho_{\mathrm{fYang}}=\rho_{\mathrm{i}} \cdot\left[1.54 \cdot 10^{-4} \cdot \mathrm{Re}^{0.351} \cdot \mathrm{Fo}^{0.311} \cdot \mathrm{w}_{\mathrm{a}}^{-0.413} \cdot\left(\frac{\mathrm{T}_{\mathrm{a}}-\mathrm{T}_{\mathrm{tp}}}{\mathrm{T}_{\mathrm{a}}-\mathrm{T}_{\mathrm{w}}}\right)\right]$

with Fo as the Fourier number, Fo $=\frac{\alpha \cdot t}{l_{c}^{2}}$ and $T_{\mathrm{tp}}$, the triple point of water.

This relation is normalized by the density of ice and strongly depends on the dimensionless temperature. Through this correlation, it can be noted that authors do not consider mass diffusion as the only phenomenon responsible for frost densification (the exponent of the time is 0.311 instead of 0.5 ). Compared to their experimental data, the correlation provides frost density with an error of $10 \%$.

The last relation is a semi-empirical relation proposed by Hermes et al. (2014). Empirical model and experimental data were used to obtain this correlation.

$\rho_{\mathrm{f}_{\text {Hermes }}}=2.2 \cdot\left[\frac{c_{\mathrm{p}} \cdot\left(\mathrm{T}_{\mathrm{sat}, \mathrm{a}}-\mathrm{T}_{\mathrm{w}}\right)}{h_{\mathrm{sub}} \cdot\left(w_{\mathrm{a}}-w_{\mathrm{sat}, \mathrm{w}}\right)}\right]^{-1.5} \cdot \mathrm{t}^{0.5}$

This relation strongly depends on modified Jakob number $\mathrm{Ja}=\frac{c_{\mathrm{p}} \cdot\left(\mathrm{T}_{\mathrm{sat}, \mathrm{a}}-\mathrm{T}_{\mathrm{w}}\right)}{h_{\mathrm{sub}} \cdot\left(w_{\mathrm{a}}-w_{\mathrm{sat}, \mathrm{w}}\right)}$ and time. In this study, authors consider that only mass diffusion occurs in frost layer (0.5 exponent for the time) contrary to Yang and Lee (2004). This correlation shows errors with $10 \%$ bounds.

As for frost thickness, Mao et al. (1999) provide a correlation for frost density, which also depends on dimensionless position ratio. So this correlation was not studied in this paper.

Table 4 presents predictive methods for frost density with their range of application.

\subsection{Quantitative and qualitative comparisons}

This section provides quantitative and qualitative analyses. For the quantitative comparison, predictive methods are applied to frost thickness and density databases. For the qualitative comparison, each method (correlations and models) is computed for different test conditions. The first part presents the results obtained for frost thickness and the second, those obtained for frost density.

\subsubsection{Frost thickness}

Best quantitative comparison results, obtained with the Schneider (1978) correlation and Hermes et al. (2009) model, are presented in Fig. $4 \mathrm{a}$ and $4 \mathrm{~b}$.

At first sight, the Schneider (1978) correlation seems to predict experimental data with a good agreement, but all points belonging to the database are not depicted in Fig. 4. The formulation of Schneider's (1978) frost thickness correlation (Eq. 1) does not allow determining frost thickness in some particular operational conditions. Consequently, $7 \%$ of the database points were excluded. The Schneider (1978) correlation is a good predictive method when test conditions are included in the

\begin{tabular}{|c|c|}
\hline Predictive method & Range of application \\
\hline Hayashi et al. (1977) & $\begin{array}{l}-18.6 \leq \mathrm{T}_{\mathrm{w}} \leq-5^{\circ} \mathrm{C} \\
2 \leq \mathrm{v} \leq 6 \mathrm{~m} \cdot \mathrm{s}^{-1} \\
\mathrm{w}_{a}=0.0075 \mathrm{~kg} \cdot \mathrm{kg}_{\mathrm{a}}^{-1} \\
0 \leq \mathrm{t} \leq 450 \mathrm{~min}\end{array}$ \\
\hline Kandula (2012) & $\begin{array}{l}-20 \leq \mathrm{T}_{\mathrm{w}} \leq-5^{\circ} \mathrm{C} \\
10 \leq \mathrm{T}_{\mathrm{a}} \leq 22^{\circ} \mathrm{C} \\
50 \leq R H \leq 80 \% \\
0.7 \leq v \leq 2.5 \mathrm{~m} \cdot \mathrm{s}^{-1}\end{array}$ \\
\hline \multirow[t]{2}{*}{ Hosoda and Uzuhashi (1967) } & $\begin{array}{l}-20 \leq T_{w} \leq-5^{\circ} \mathrm{C} \\
0 \leq T_{a} \leq 10^{\circ} \mathrm{C}\end{array}$ \\
\hline & $\begin{array}{l}1 \leq v \leq 5 \mathrm{~m} \cdot \mathrm{s}^{-1} \\
0.00188 \leq w_{\mathrm{a}} \leq 0.00604 \mathrm{~kg} \cdot \mathrm{kg}_{\mathrm{a}}^{-1} \\
0 \leq t \leq 240 \mathrm{~min}\end{array}$ \\
\hline Yang and Lee (2004) & $\begin{array}{l}-35 \leq T_{\mathrm{w}} \leq-15^{\circ} \mathrm{C} \\
-5 \leq \mathrm{T}_{\mathrm{a}} \leq 15^{\circ} \mathrm{C} \\
1.0 \leq \mathrm{v} \leq 2.5 \mathrm{~m} \cdot \mathrm{s}^{-1} \\
0.00322 \leq w_{\mathrm{a}} \leq 0.00847 \mathrm{~kg} \cdot \mathrm{kg}_{\mathrm{a}}^{-1}\end{array}$ \\
\hline \multirow[t]{2}{*}{ Hermes et al. (2014) } & $\begin{array}{l}-15 \leq \mathrm{T}_{\mathrm{w}} \leq-5^{\circ} \mathrm{C} \\
16 \leq \mathrm{T}_{\mathrm{a}} \leq 22^{\circ} \mathrm{C} \\
v=0.7 \mathrm{~m} \cdot \mathrm{s}^{-1} \\
5 \leq \mathrm{RH} \leq 80 \%\end{array}$ \\
\hline & $0 \leq t \leq 120 \mathrm{~min}$ \\
\hline
\end{tabular}

data range. For other environmental conditions, another predictive method is required. Results displayed in Fig. $4 \mathrm{~b}$ are obtained with the Hermes et al. (2009) model. Results are more scattered than those obtained with Schneider (1978). For some data, the Hermes et al. (2009) model can predict frost thickness with a good agreement, but for others, the error committed can be significant. But, contrary to Schneider (1978), no operational conditions are ignored.

To complete the results, the percentage of the data points within a $\pm 20 \%$ error band (PERC), the mean absolute error (MAE) and the mean relative error (MRE) are specified on Fig. $4 \mathrm{a}$ and 4b. Table 5 presents PERC for each experimental database and each predictive method.

Lee et al.'s (1997) model seems to be the less reproducible predictive method. It is probably due to the hypothesis for the initial frost thickness and density. The Schneider (1978) cor-

Table 5 - Percentage error band for frost thickness prediction (bold values correspond to best model prediction for each experimental data).

\begin{tabular}{lrrrr} 
Experimental data* & \multicolumn{4}{c}{ Model (\%) } \\
\cline { 2 - 5 } & $\begin{array}{c}\text { Hermes } \\
\text { et al. }\end{array}$ & $\begin{array}{c}\text { Lee } \\
\text { et al. }\end{array}$ & $\begin{array}{c}\text { Schneider } \\
(1978)\end{array}$ & $\begin{array}{c}\text { Hermes } \\
(2012)\end{array}$ \\
& $(2009)$ & $(1997)$ & & \\
\hline Jones and Parker (1975) & 26.7 & 19.0 & 14.3 & 42.9 \\
Kandula (2012) & 100.0 & 80.0 & 100.0 & 40.0 \\
Cai et al. (2011) & 0.0 & 0.0 & 83.3 & 0.0 \\
Lee et al. (2003) & 23.8 & 0.0 & $64.3^{*}$ & 19.1 \\
Wang et al. (2012) & 55.6 & 38.9 & $66.2^{*}$ & 35.6 \\
Yonko and Sepsy (1967) & 31.5 & 17.8 & 47.9 & 37.0 \\
Hermes et al. (2009) & 87.4 & 1.1 & 83.9 & 87.4 \\
Lee et al. (1997) & 55.0 & 47.5 & 87.5 & 47.5 \\
Total of data points & 54.9 & 23.8 & 66.7 & 40.7 \\
\hline * Data points excluded for Schneider model. & & \\
\hline
\end{tabular}




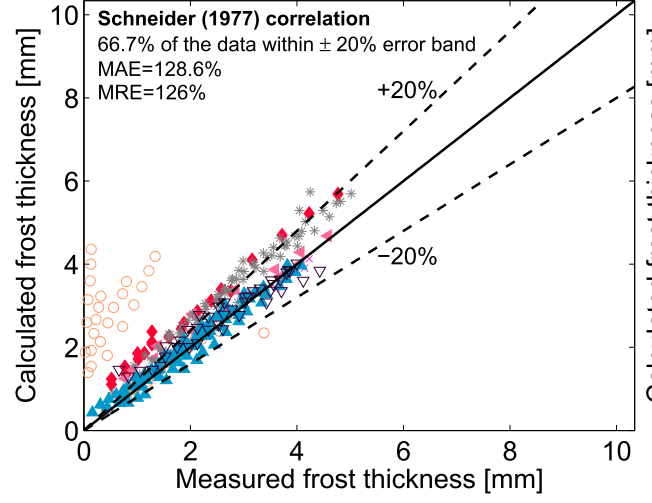

(a) Schneider (1978) correlation

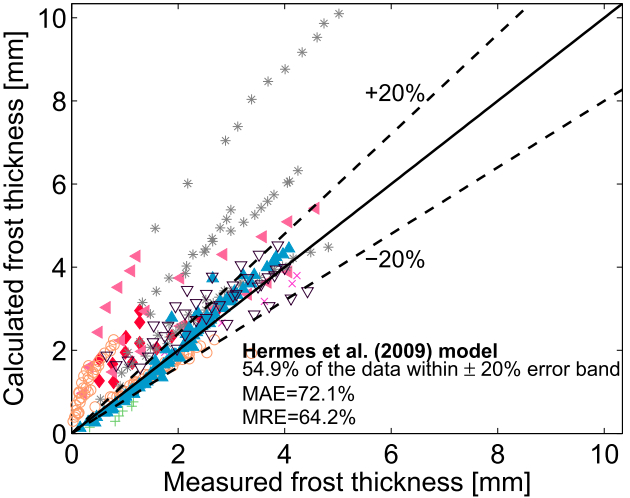

(b) Hermes et al. (2009) model

Fig. 4 - Predictive methods applied to frost thickness database (points legend in Table 1).

relation, and the Hermes et al. (2009) and Hermes (2012) models show good agreement with experimental data points. Nevertheless, improvements are still needed in this field in order to propose a non restrictive predictive method.

This quantitative comparative study is completed with a qualitative comparison.

Fig. 5 shows results for air velocities of $0.5 \mathrm{~m} \mathrm{~s}^{-1}$ and $2 \mathrm{~m}$ $\mathrm{s}^{-1}$. The other experimental conditions are kept constant.

Results are found to be more scattered for low velocities than for high velocities. This work shows that some improvements are needed to extend models and correlations to low velocities.

Fig. 6 shows the same test with relative humidity as varying parameter. As for velocity, predictive methods present less scattering for higher relative humidity. The higher the relative humidity is, the better is the agreement with correlations and models. The simulations were also conducted for the wall temperature as the varying parameter. The figures are not provided in the paper but the same conclusions were made: the lower the wall temperature, the lower the scattering.

\subsubsection{Frost density}

The same work applied to frost density database is presented in this section. As a reminder, Lee et al.'s (2003) experimental data were excluded in this study.
Results of the quantitative comparative study obtained for each correlation are presented in Table 6. According to this table, it can be noted that predictions for frost density are less efficient than for frost thickness. The two best results are presented in Fig. 7a and 7b. Best prediction methods are Yang and Lee (2004) and Hermes (2012) correlations.

The more accurate prediction methods can only predict $28 \%$ of the database. Facing these unsatisfactory results, the authors of the present study proposed a new empirical correlation, determined with the 149 data points presented previously. The correlation is as follow:

$\rho_{\mathrm{f}}=5.47 \cdot \operatorname{Re}^{0.16} \cdot \mathrm{Ja}^{0.29} \cdot \frac{{\frac{w_{\mathrm{w}}}{w_{\mathrm{a}}}}^{0.61}}{w^{0}} \cdot \mathrm{t}^{0.34}$

where $\operatorname{Re}=\frac{\rho_{\mathrm{a}} \cdot v_{\mathrm{a}} \cdot l_{\text {plate }}}{\mu}$ is the Reynolds number, $\mu$ is the dynamic viscosity of air and $\mathrm{Ja}=\frac{c_{\mathrm{p}}\left(\mathrm{T}_{\mathrm{a}}-\mathrm{T}_{\mathrm{w}}\right)}{h_{\mathrm{sub}}\left(w_{\mathrm{a}}-w_{\mathrm{w}, \text { sat }}\right)}$ is the modified Jakob number. $T_{a}$ is the temperature of humid air, $T_{w}$ is the wall temperature, $w_{\mathrm{a}}$ is the absolute humidity of the air taken at $T_{\mathrm{a}}$ and $w_{\mathrm{w}, \mathrm{sat}}$ is the absolute humidity taken at $\mathrm{T}_{\mathrm{w}}$ at saturation ( $100 \%$ of humidity). $\rho_{\mathrm{a}}, \mu, c_{\mathrm{p}}$ and $h_{\text {sub }}$ are taken at the humid air temperature.

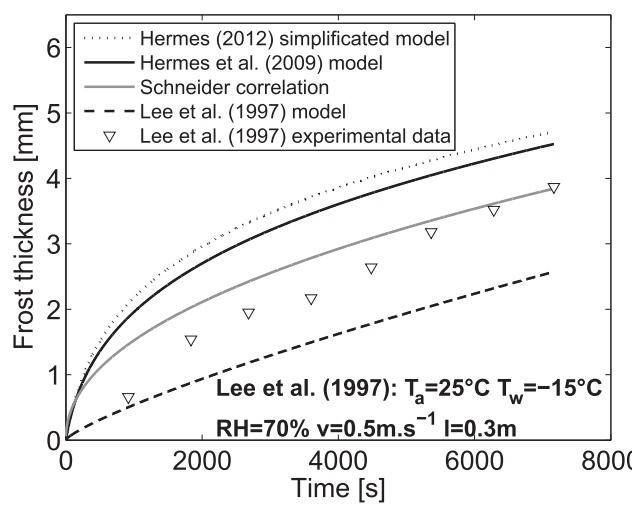

(a) Low velocity

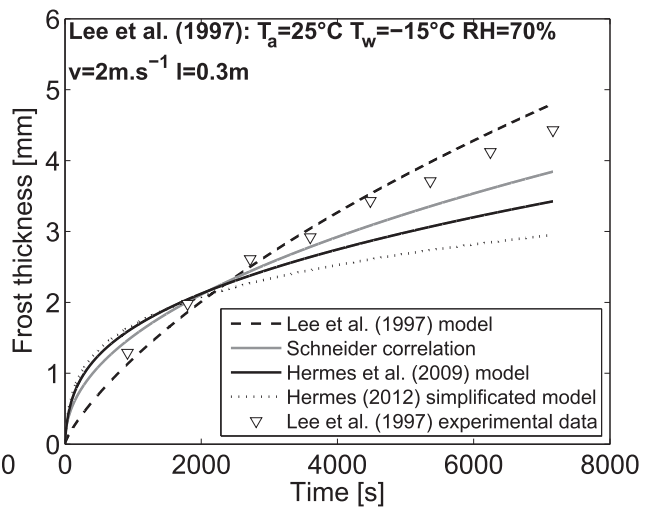

(b) High velocity

Fig. 5 - Qualitative comparison for frost thickness: velocity case. 


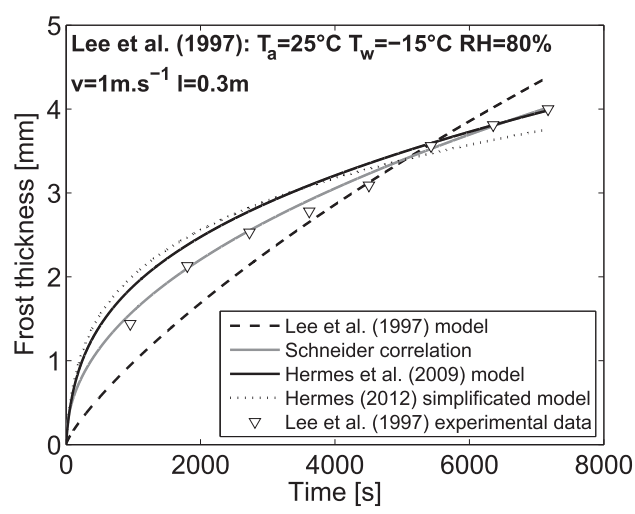

(a) High relative humidity

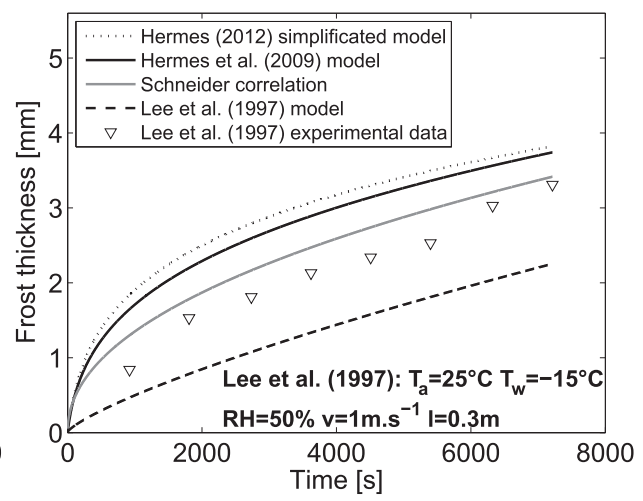

(b) Low relative humidity

Fig. 6 - Qualitative comparison for frost thickness: relative humidity case.

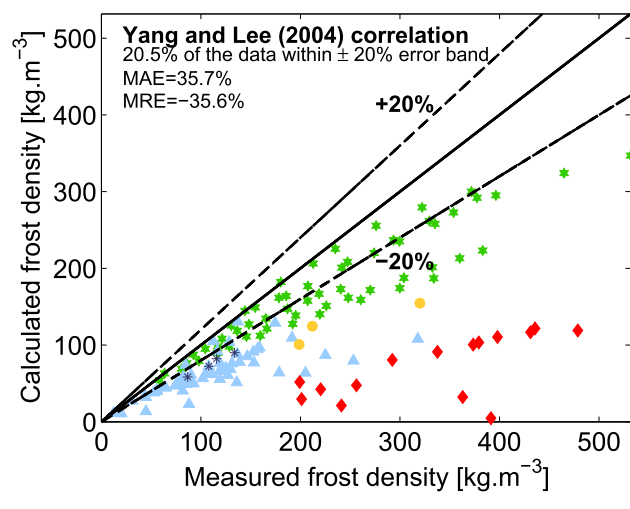

(a) Yang and Lee (2004) correlation

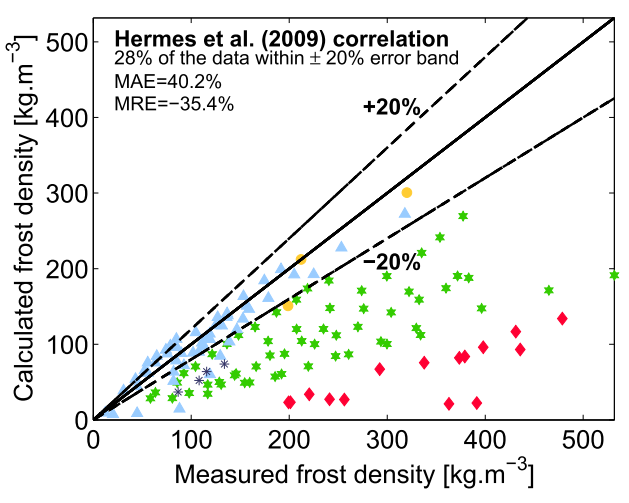

(b) Hermes (2012) correlation

Fig. 7 - Predictive methods applied to frost density database (points legend in Table 2).

Applied to the database, the present correlation shows better agreement with experimental data (Fig. 8). This correlation is based on Reynolds number, modified Jakob number (inspired by Hermes et al.'s [2009] study), water quantity ratio in humid air and time. Therefore, main parameters as air velocity, wall temperature and relative humidity are taken into account. As for Yang and Lee (2004) and contrary to Hermes (2012), the time exponent is found to be 0.34 and therefore different to 0.5 (the correlation with a 0.5 exponent only predicts $37.1 \%$ of the database). It means that in most of the studies, it cannot be considered that only mass diffusion is occurring during frost densification.

Table 6 - Results of quantitative study for frost density (bold values correspond to better predictive method).

\begin{tabular}{lrrc} 
Model & \multicolumn{3}{c}{ Statistics (\%) } \\
\cline { 2 - 4 } & MAE & MRE & PERC \\
\hline Hayashi et al. (1977) & 61.4 & -24.8 & 14.5 \\
Kandula (2012) & 87.9 & 7.0 & 10.6 \\
Hosoda and Uzuhashi (1967) & 121.8 & 120.2 & 13.6 \\
Hermes (2012) & 40.2 & 35.4 & 28.0 \\
Yang and Lee (2004) & 35.7 & 35.6 & 20.5 \\
\hline
\end{tabular}

Of the points of the database, $56.8 \%$ are included in the $\pm 20 \%$ error band. The present correlation allows doubling number of predictions included into the range.

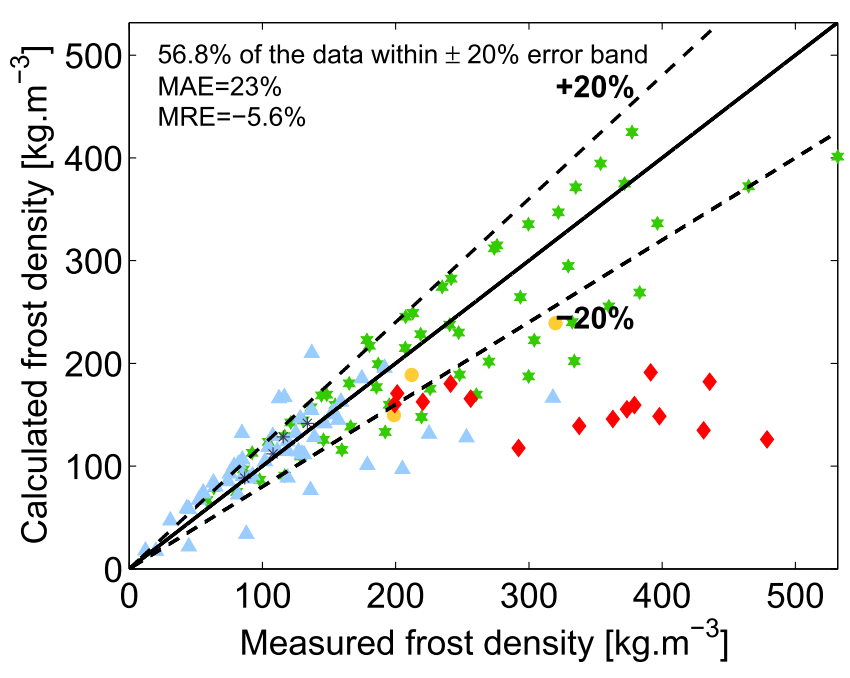

Fig. 8 - Present correlation applied to frost density database. 


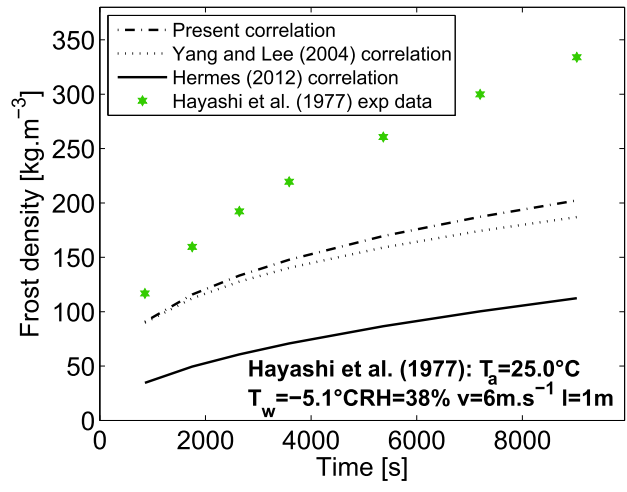

(a) High wall temperature

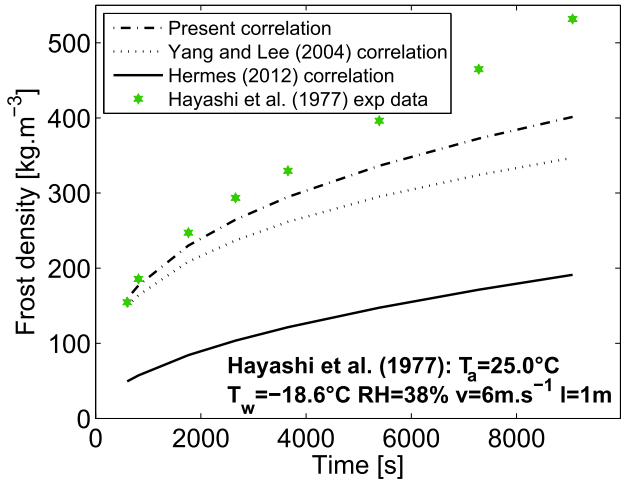

(b) Low wall temperature

Fig. 9 - Qualitative comparison for frost density: wall temperature.

Comparing density and thickness studies, it can be noted that for frost density, there is a real lack of experimental data point. Indeed, additional data are required to be sure that present correlation is not too much impacted by a set of one author data.

The following paragraph presents results of the qualitative study for frost density. Only results for air velocity and wall temperature are included in the present section. In fact, based on experimental data, the present authors are not able to conclude concerning the impact of relative humidity on frost density. It seems not relevant to compare predictive methods to experimental data point without having the knowledge of the physical phenomenon. Based on the previous conclusions, Hosoda and Uzuhashi (1967), Kandula (2012) and Hayashi et al. (1977) correlations are not taken into account in this part because of the weak results obtained previously.

Fig. 9 shows predictions of the correlations for two tests with different wall temperatures. It can be observed that experimental points are better predicted for low wall temperature. Concerning each correlation, that from Hermes (2012) is found to be the less representative for the Hayashi et al. (1977) data points. In both cases, present correlation shows the best prediction.

Fig. 10 presents the same work with velocity as variable parameter. Results are more scattered for high velocity. Again, present correlation is found to be the best predictive method.

\subsubsection{Synthesis}

Frost thickness is found to increase:

- when velocity increases

- when relative humidity increases

- when wall surface temperature decreases

Frost layer is denser:

- when wall temperature is higher

- when velocity is higher

No relation could be established between relative humidity and frost density because of contradictory information. Correlations and models available in the literature can predict frost thickness satisfactorily but improvements are still needed to obtain predictions with better accuracy. To identify the weaknesses of the current studies, the authors propose to list the main hypothesis chosen by authors of the best predictive model (Hermes et al., 2009) and discuss the possible error sources.

- Hermes et al. (2009) use an empirical correlation to calculate frost density. Disparities between frost density results from the different studies can explain why the Hermes et al. (2009) model can predict well their own experiments but predict with less accuracy experiments of other authors.

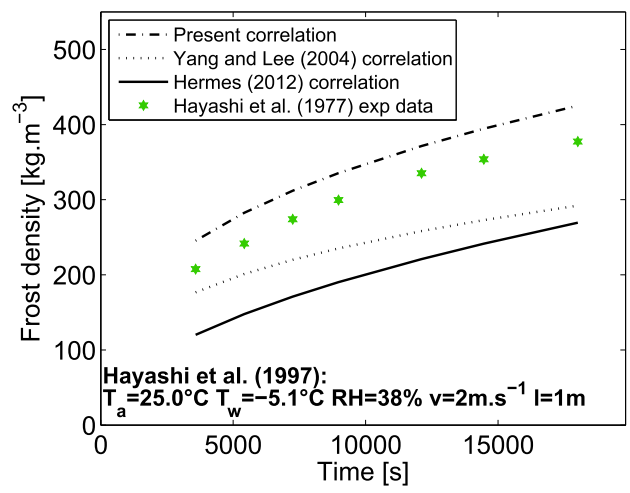

(a) Low velocity

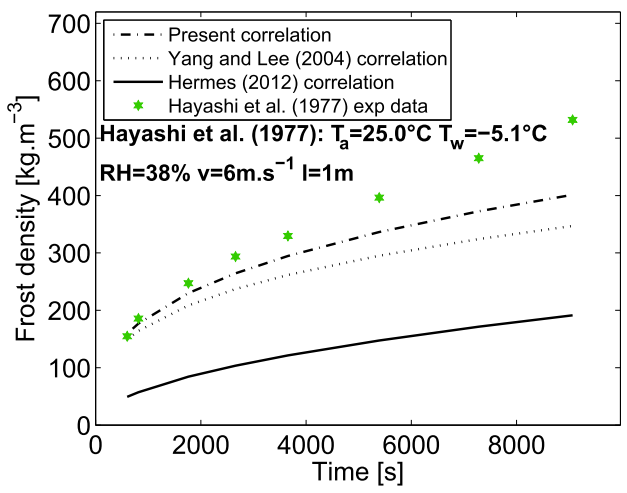

(b) High velocity

Fig. 10 - Qualitative comparison for frost density: velocity case. 
Generally speaking, correlations based on limited databases are extrapolated to larger sets of data.

- Another assumption concerns diffusion of the water vapour in the frost layer, considered as a porous media. In fact, Hermes et al. (2009) considered that effective diffusion drives layer thickening and densification to the frost. Maybe diffusion is not the only phenomenon occurring but advection may also take place in the frost layer. This would explain why time exponent of present correlation (only based on experimental results) is different from 0.5 . It could be interesting to calculate the Sherwood number in order to evaluate the impact of advection in the frost layer. If advection contribution is found sizeable, advection term should be added in the energy balance equation. For frost density, predictive methods are less efficient as frost thickness. Hermes (2012) ventures the same hypothesis as his previous study, which can partly explain the results obtained.

Both previous items led to identifying a first source of discrepancy between correlations and measurements: physical phenomena that occur during frost formation and development are not all taken into account in correlations. Bias between experimental and calculated values can also stem from experimental data. Errors that can occur during experimental tests are listed below:

- Experimental setup can lead to a non-uniform cold plate temperature. This non-uniformity can be responsible for a non homogeneous formation of frost. Values obtained for thickness and density can be less precise than expected and hypothesis of one-dimensional formation of frost used in predictive methods is no longer suitable.

- Frost surface temperature is a parameter that is difficult to measure; most of the time infrared thermometers are used. These thermometers allow obtaining temperature in one point but not the temperature of the whole surface. If the temperature distribution is not homogeneous, temperature measured is erroneous.

- Heat flux transfered between air and cold surface is also difficult to measure and leads to possible errors.

- In most experimental studies, surface characteristics (i.e. rugosity and contact angle) are not provided. However, these parameters are found to have a significant impact on frost nucleation. As these parameters are rarely provided, they are not taken into account in correlations which can also explain discrepancies between measured and calculated data.

Despite numerous numbers of papers about frost formation, some improvements need to be done. Historically, a major part of the studies focused on frost thickness, which explains better results in this field. Studies about frost density are more recent, and therefore, need to be pursued both experimentally or model development. Generally speaking, articles dealing with experimental studies should better explain their experimental procedure (i.e. how to start the measurements under steady state conditions without frost formation on the surface) and their measurements (i.e. how is the weight measured, uncertainty). As for the models, it was shown that some methods were not able to be reproduced. As a result, the authors should clearly define each term used in the equation and suggest one test case to check the accuracy of their model.

\section{Extension to vertical plates}

Most of the studies concern horizontal flat plates. But some authors trying to approach industrial issues decided to work on more complex geometries, like vertical plates. This section presents a similar work for this geometry. This section aims at comparing flat plate predictive methods to vertical plates data.

\subsection{Database presentation}

For the case of vertical plates, database has the same form as horizontal plate's database. Eighty-eight points are listed for frost thickness and 122 for frost density. Data points are taken from studies by Lee and Ro (2002); El Cheikh and Jacobi (2014); Janssen et al. (2012); Fossa and Tanda (2010) and Yamashita et al. (2007).

\subsection{Impact of environmental parameters}

The impact of environmental parameters is presented. The aim is not only to evaluate consequence of wall temperature, relative humidity and air velocity on frost thickness and density, but also to compare observations for the vertical plate with those of horizontal plate. Fig. 11 shows that frost thickness increases with low wall temperature, high air velocity and high relative humidity. The same observations were made for horizontal plates.

Results for frost density are presented in Fig. 12. Contrary to thickness, density decreases with low wall temperature. Concerning air velocity, frost density follows the same behaviour as for frost thickness. Fig. 12c brings additional information. In fact, results for horizontal plate did not allow the authors of the present study to conclude for the impact of relative humidity on frost density. For vertical plate, results obtained for the two authors (Lee and Ro, 2002 and El Cheikh and Jacobi, 2014) are in agreement. In fact, frost density is found to increase with lower relative humidity.

\subsection{Quantitative and qualitative comparison}

\subsubsection{Frost thickness}

For the quantitative comparison, the best models and correlations determined in the first section are applied to thickness and density databases. Fig. 13 presents quantity of data points included in the $\pm 20 \%$ range. It can be observed that predictive methods for frost thickness development on horizontal plate cannot be applied to vertical plate. In fact, percentages are $4.4 \%$ and $2.2 \%$, respectively.

For the qualitative comparison, predictive methods are applied to a set of experimental data for different environmental parameters. Fig. 14 shows results obtained for wall temperature and relative humidity. Comparing Figs. 14a and $14 \mathrm{~b}$, it can be observed that predictive methods are better when relative humidity is lower. Concerning wall temperature, predictive methods are found to be far away from experimental data. As illustrated in the previous part, predictive methods of frost thickness are not accurate for vertical plates. The same conclusions were found concerning air velocity, taking into account Lee and Ro's (2002) experimental data. 


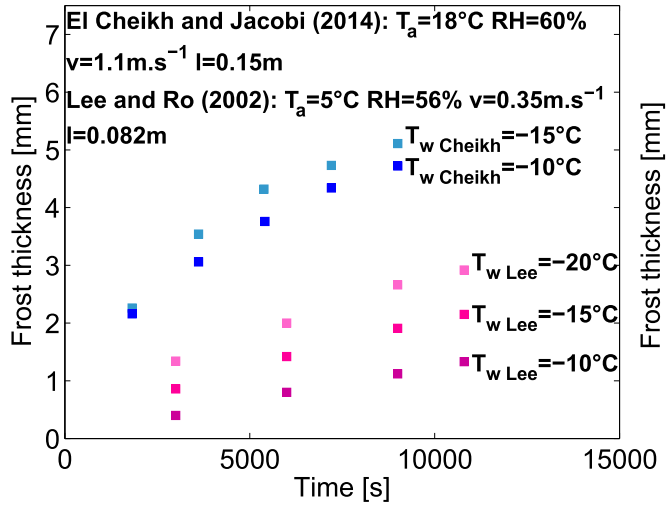

(a) Wall temperature

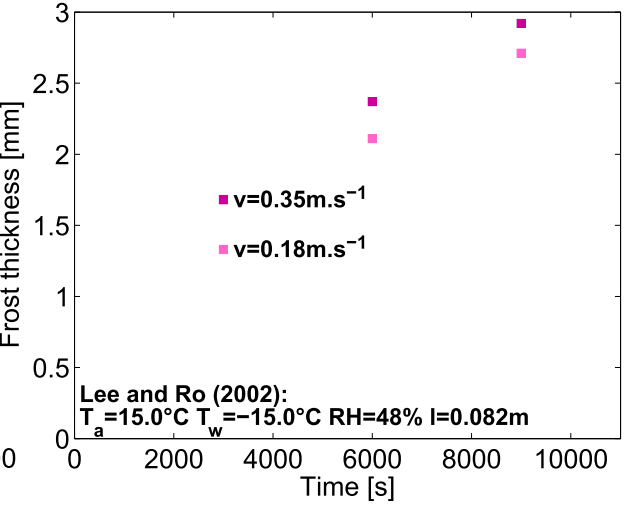

(b) Air velocity

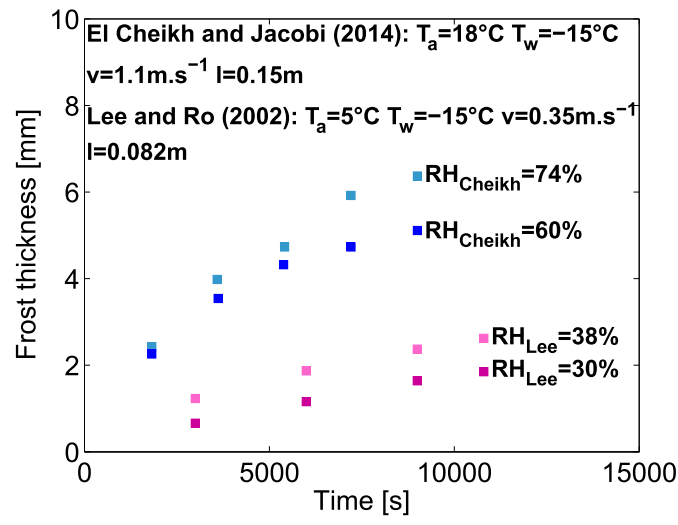

(c) Relative humidity

Fig. 11 - Impact of environmental parameters on frost thickness.

\subsubsection{Frost density}

The quantitative comparison shows more convenient results using the correlation proposed in the present study (Eq. 10). In fact, Fig. 15 shows that $36.1 \%$ of the data points are included in the $20 \%$ range. However, frost density correlation is not as appropriate as for horizontal plate.

Additional tests are required with vertical geometry to find a new relation for calculating frost density and strengthen present correlation.

Results of the qualitative comparison for frost density are shown on Figs. 16 and 17. Fig. 16 presents results obtained with predictive methods applied to two data points of Lee and Ro (2002) varying from relative humidity. Only the correlation proposed in the present study shows satisfactory results. In fact, the Hermes (2012) and Yang and Lee (2004) correlations are not adapted to vertical plates geometry. No predominance of the impact of high or low relative humidity on predictive methods is found. Results seem a few less scattered for higher relative humidity. But the two tests are too close to bring strong conclusions.

Fig. 17 presents the same study with wall temperature as varying parameter. For this test, results are more obvious. In fact, the present correlation is found to be more efficient for low wall temperature. Tests with higher wall temperatures show a higher scattering between measured and calculated values. However, some hesitation is expressed as for the validity of high wall temperature tests. The two other correlations are still not convenient.

\subsubsection{Synthesis}

Frost thickness on vertical plate increases (same conclusions as for horizontal plates):

- when relative humidity is higher

- when wall surface temperature is lower

Frost density increases:

- when wall surface temperature increases

- when velocity increases

- when relative humidity decreases (this observation is in opposition with Hermes et al.'s (2009) results of the first part)

For vertical plates, correlations and models established for flat plates cannot be used to predict frost development. Some of Hermes et al.'s (2009) hypothesis can explain it. For the horizontal plate case, authors assume that frost thickness is uniform along the plate length and processes of mass and heat diffusion within the frost layer are one-dimensional. These assumptions are not convenient for vertical plates because of gravity effect. In fact, when environmental condition leading to condensation and solidification is gathered (i.e. surface 


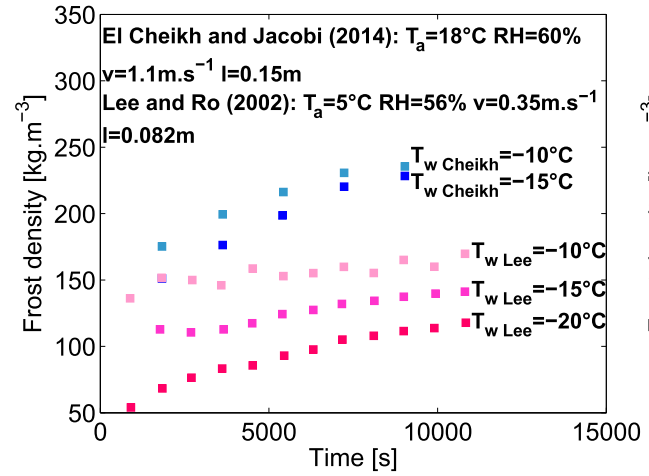

(a) Wall temperature

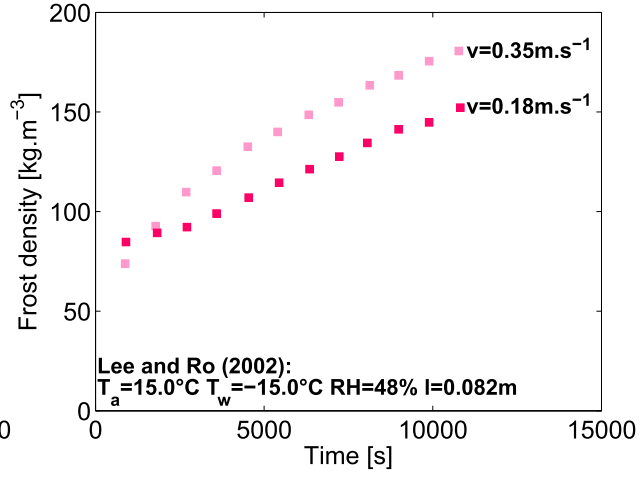

(b) Air velocity

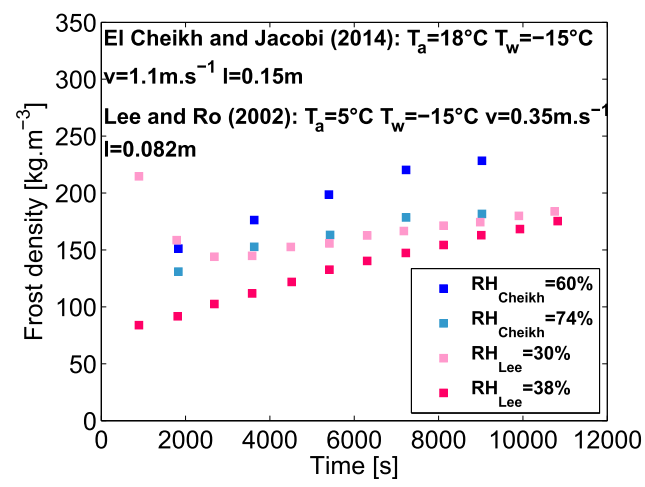

(c) Relative humidity

Fig. 12 - Impact of environmental parameters on frost density.

temperature below the triple point of water and dew temperature greater than the latter), liquid droplets at the surface and inside the frost layer will suffer gravity effects. Droplets will flow along the plate length, leading to a non homogeneous frost layer. Frost layer can no longer be considered uniform along the plate length. So, the influence in the airflow axis should not be neglected and experimental data should be expressed as a function of the distance from the leading edge of the plate. Other sources of discrepancy between measured data and corrections are listed in the first section. Frost formation on vertical plates needs a deeper investigation. In fact, this configuration is closer to industrial application than horizontal plate studies. Most of the time, fins of heat exchangers are vertically set, which implies to take into account gravity effect. New experimental investigations are needed to complete the existing databases. A comparison between vertical and horizontal results could lead to the identification of gravity impact. It could also be interesting to work on other orientation angles of the plate. It could serve to gradually observe the impact of the gravity.

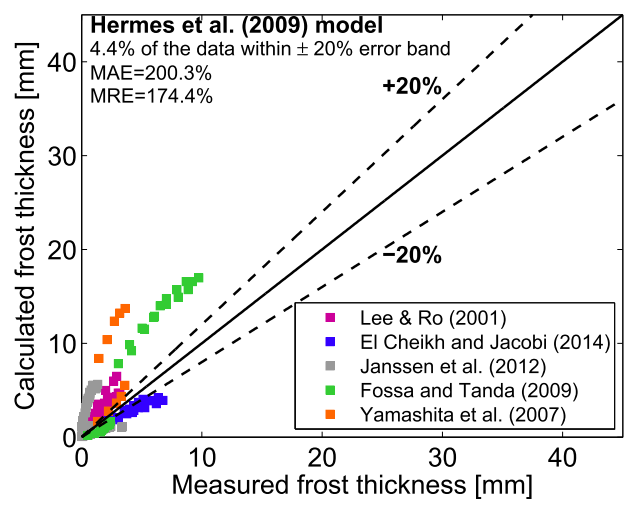

(a) Hermes et al. (2009)

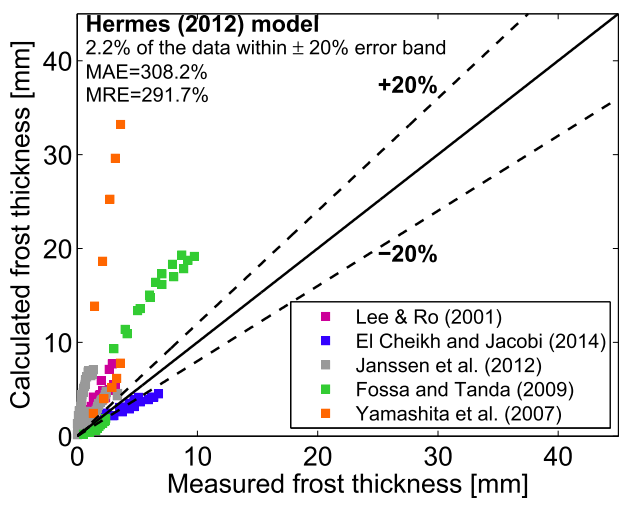

(b) Hermes (2012)

Fig. 13 - Predictive methods applied to vertical plate database frost thickness. 


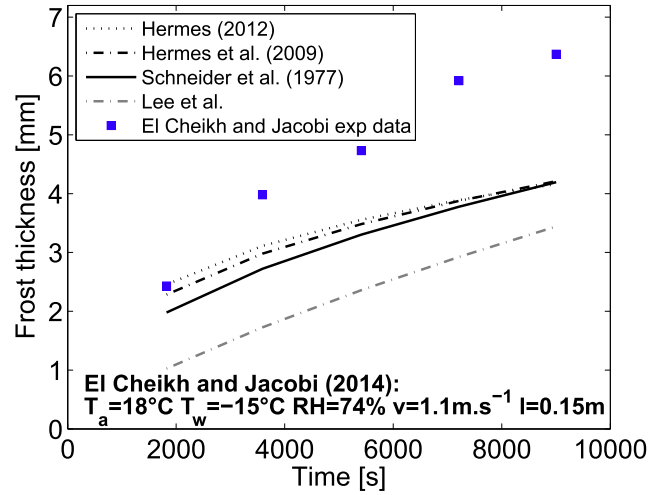

(a) Wall temperature

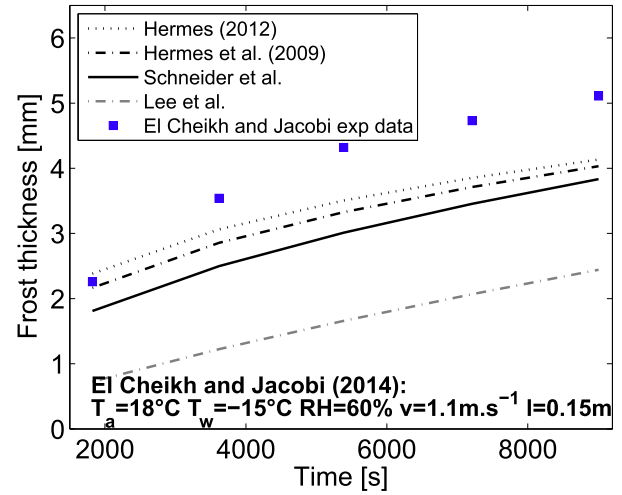

(b) Air velocity

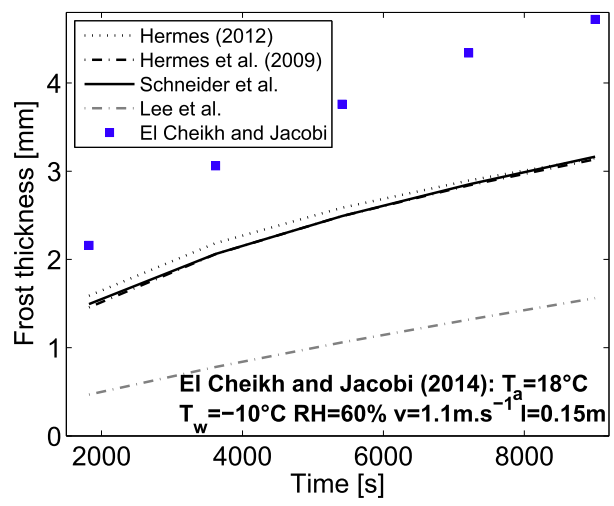

(c) Relative humidity

Fig. 14 - Qualitative comparison for frost thickness: relative humidity and wall temperature case.

\section{Extension to parallel plates}

\subsection{Database presentation}

This section aims at comparing flat predictive methods to parallel plates data. Frost thickness database for parallel plates

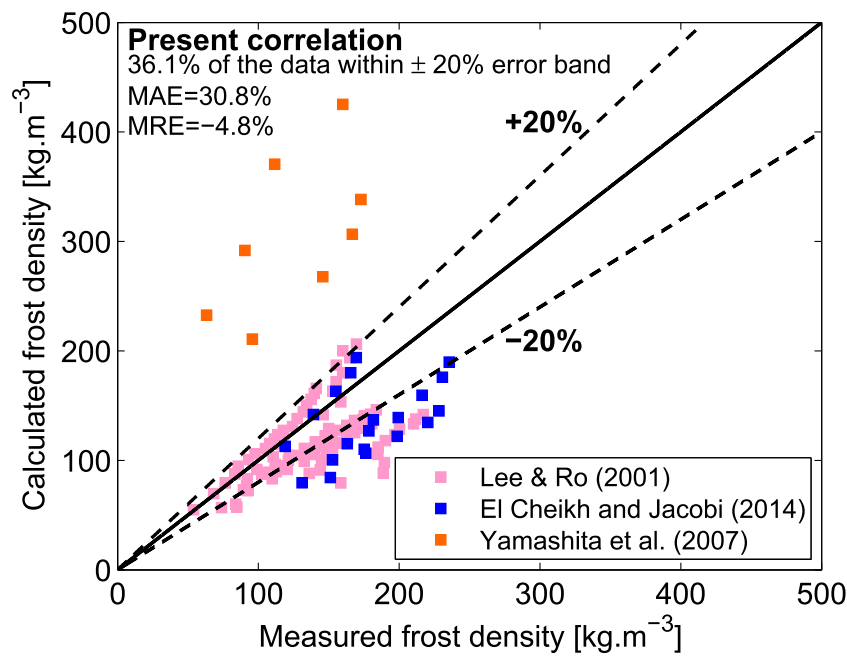

Fig. 15 - Correlation applied to vertical plate database frost density. is composed of 24 data points from Ostin and Andersson (1991). For frost density, database is made up of 25 data points gathered from 2 authors: the previous one and Nascimento et al. (2015). Both authors realized experiment on horizontal parallel plates (Fig. 18). Ostin and Andersson (1991) did not provide distance between the two plates. The only information is that the section area can be modified. Nascimento et al. (2015) also worked on a varying section. Distance between the two plates could vary between $8.4 \mathrm{~mm}$ and $19.0 \mathrm{~mm}$.

\subsection{Impact of environmental parameters}

Fig. 19 presents the impact of wall temperature and relative humidity on frost thickness. As for the previous test of environmental impact, frost layer is found to be thicker with low wall temperature and high relative humidity. The impact of wall temperature on frost thickness is the same for all geometries (single horizontal, single vertical, horizontal parallel plates). Concerning relative humidity, conclusions are not strong. In fact, excluding Wang et al.'s (2012) experimental results, it can be considered that both simple and double horizontal plates have the same behaviour (frost thickness increases with relative humidity) - and the opposite conclusion is observed from vertical plates. The impact of air velocity study could not be led because of lack of experimental tests for parallel plates.

Fig. 20 shows impact of air velocity of frost density. Results agree with conclusions made for horizontal and vertical plates: 


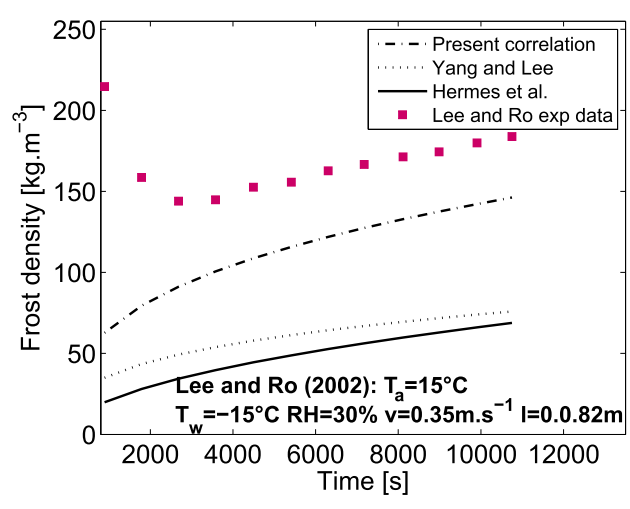

(a) Low relative humidity

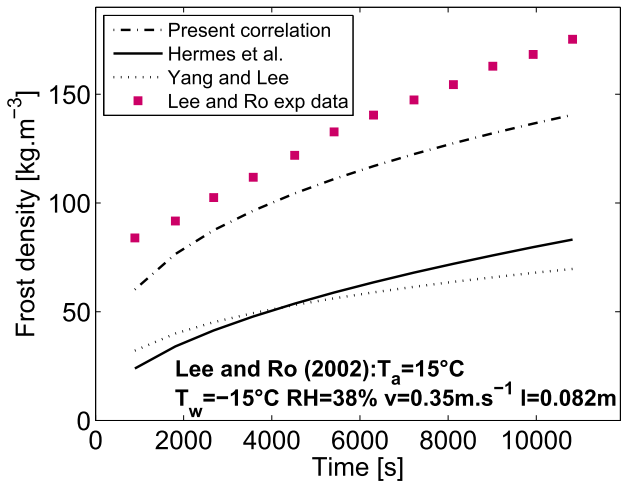

(b) High relative humidity

Fig. 16 - Qualitative comparison for frost density: relative humidity case.

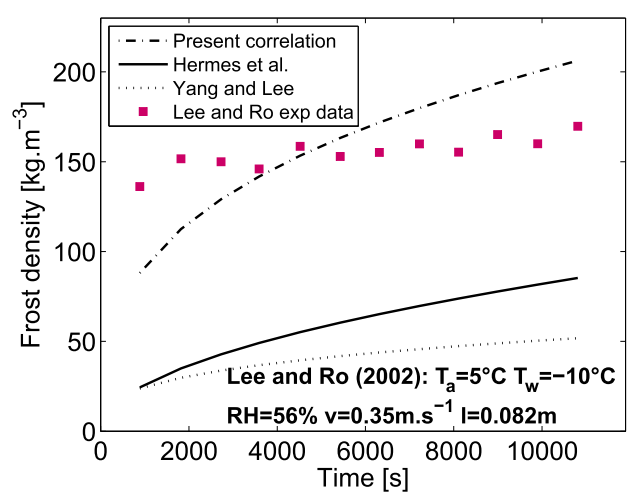

(a) High wall temperature

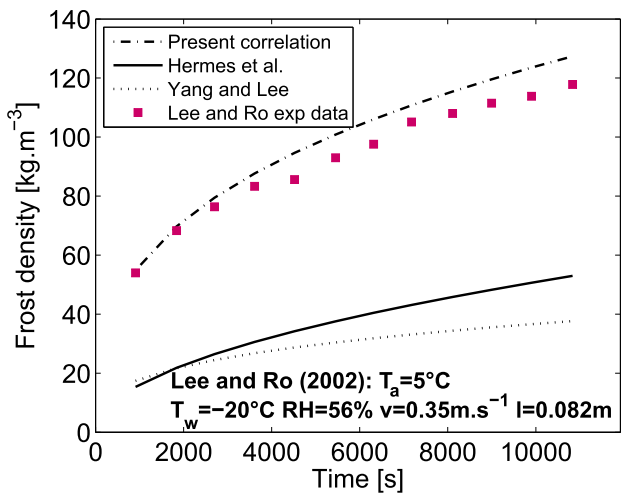

(b) Low wall temperature

Fig. 17 - Qualitative comparison for frost density: wall temperature case.

frost density increases with air velocity. The same study could not be carried out for wall temperature and relative humidity influence especially as experimental data of Nascimento et al. (2015) were not usable for this kind of experiment. In fact, data point number was weak and test conditions were very variable that make two by two comparisons difficult.

\subsection{Quantitative and qualitative comparison}

\subsubsection{Frost thickness}

Fig. 21 presents ratio of data points included in the percentage of $\pm 20 \%$ for Hermes et al. (2009) (Fig. 21a) and Hermes (2012) correlations (Fig. 21b). The results for the quantitative comparative study are satisfactory. Percentages are $54.2 \%$ and $29.2 \%$

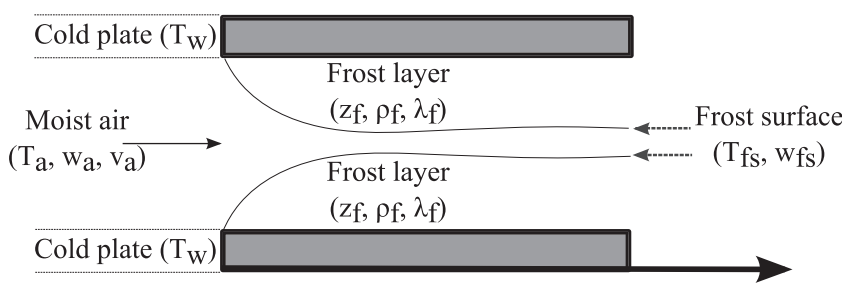

Fig. 18 - Experiment with horizontal parallel plates. respectively. Hermes et al.'s (2009) frost thickness model for horizontal plates can also be used for horizontal parallel plates.

Fig. 22 shows qualitative comparison results: the present correlations are applied to Ostin and Andersson (1991) data. As for vertical plate, best correlations are found to be from Hermes et al. (2009) and Schneider (1978). Results are more scattered for low wall temperature.

No tests were led for air velocity and relative humidity because of lack of data.

\subsubsection{Frost density}

The results of the quantitative comparison for frost density are presented in Fig. 23. The results are only depicted for author's correlation that showed the best results. The Yang and Lee (2004) and Hermes et al. (2014) correlations exhibit only $28.0 \%$ and $12.0 \%$ of data points within a $\pm 20 \%$ error band. The present correlation gives little satisfactory results: percentage of data points within a $\pm 20 \%$ error band is $32.0 \%$. In fact, only one third of the data can be predicted and the MAE and MRE are very high. Authors see that flat plates correlations cannot be applied to parallel plates. Based on this observation, Nascimento et al. (2015) proposed a specific correlation for this kind of geometry which gives a better agreement with their data.

Qualitative comparison is only depicted for velocity case (Fig. 24). Results are more scattered than for frost thickness. Present correlation shows better results for low velocities. This figure 


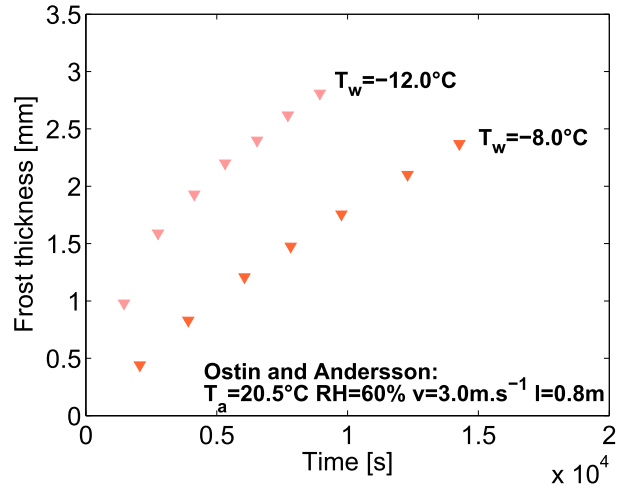

(a) Wall temperature

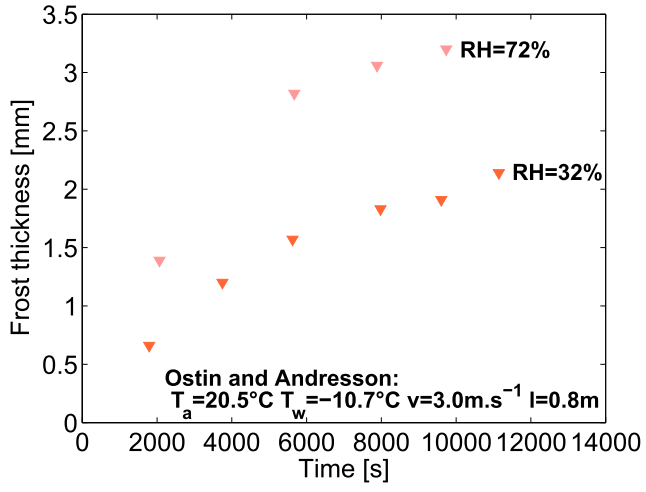

(b) relative humidity

Fig. 19 - Impact of environmental parameters on frost thickness.

also shows that frost density decreases with the velocity augmentation. An opposite result was found for horizontal single plate. In fact, heat transfer coefficient is higher with high air velocity, which increases surface plate temperature. When the

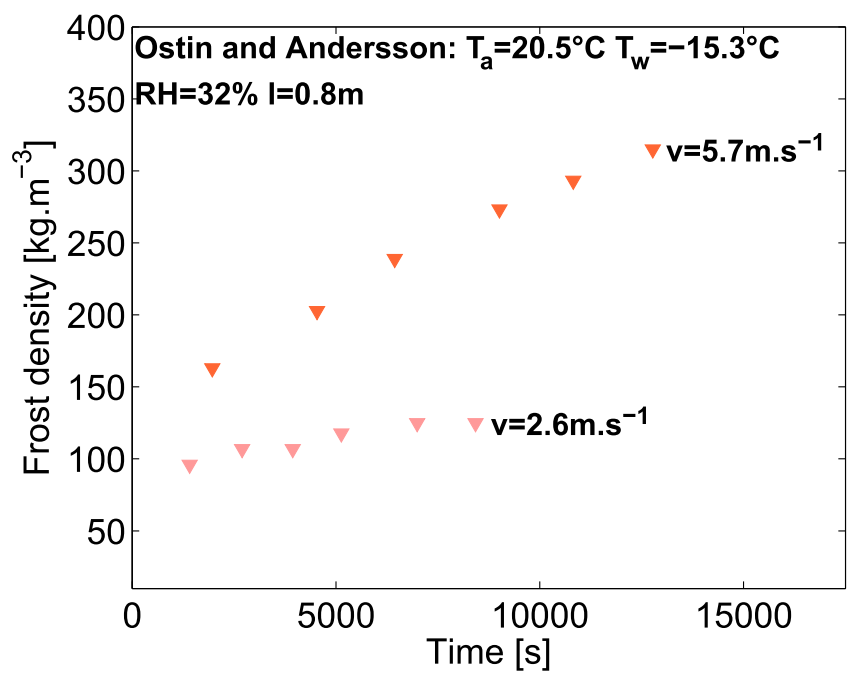

Fig. 20 - Impact of environmental parameters on frost density: air velocity.

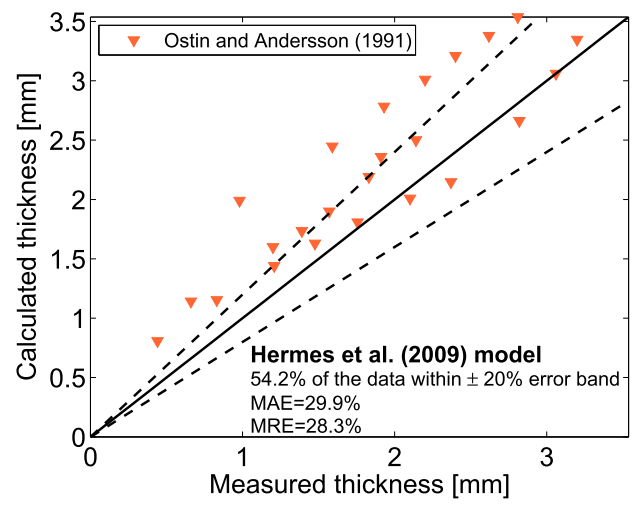

(a) Hermes et al. (2009) surface temperature is higher, less frost is deposited. However, high velocity leads also to higher mass transfer coefficient yielding an increase of mass deposition. Thus, velocity leads to two oppposite phenomena: one inhibits and the second stimulates frost deposition.

\subsubsection{Synthesis}

A few number of studies concerning parallel configurations do not lead to strong conclusions. Similar behaviours as those detected on other geometries are observed: i.e. frost thickness increases with low wall temperature. That from Hermes et al. (2009) is found to be the best non-excluding predictive method. Error sources between experimental points and correlations are provided in the first section. In addition, results are not as satisfactory as for single horizontal plate because the second plate influences frost formation and the boundary layers. In fact, owing to proximity between both plates, dynamic and thermal boundary layers are impacting each other. In the case of single plate, free flow without any thermal disturbance is considered.

\section{Conclusion}

This paper provides a comparative study of predictive methods of frost growth and data points obtained in literature for three

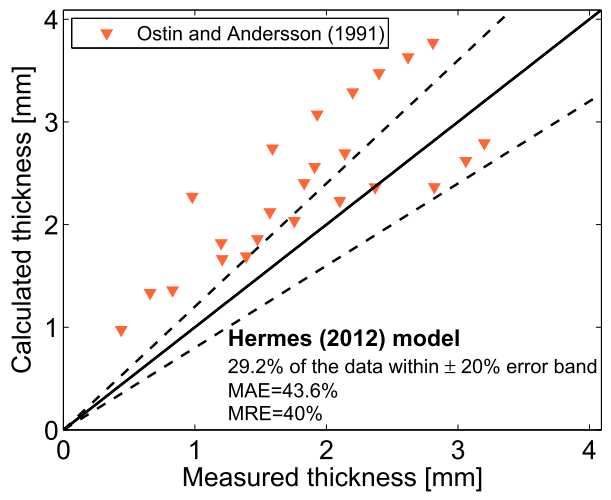

(b) Hermes (2012)

Fig. 21 - Predictive methods applied to parallel plate database. 


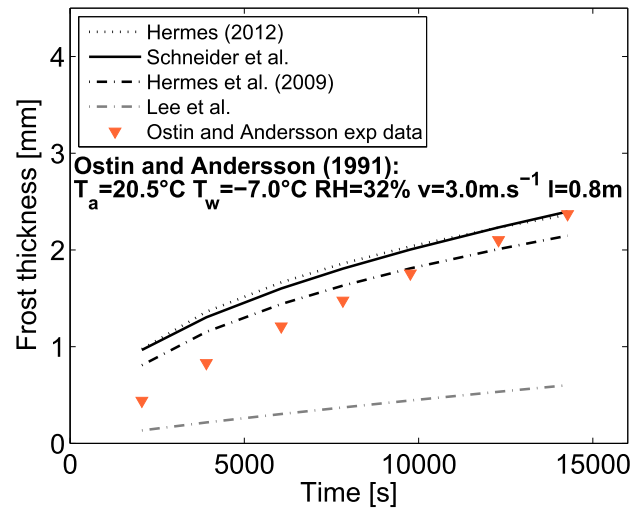

(a) High wall temperature

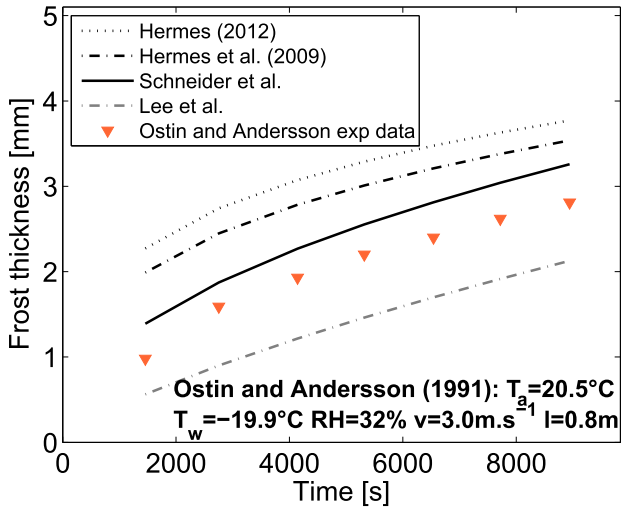

(b) Low wall temperature

Fig. 22 - Qualitative comparison: wall temperature case.

different geometries: horizontal flat plate, vertical flat plate, horizontal parallel flat plates. Considering the three geometries, 494 points were gathered for thickness and 296 for frost density. For each geometry, the impact of environmental pa-

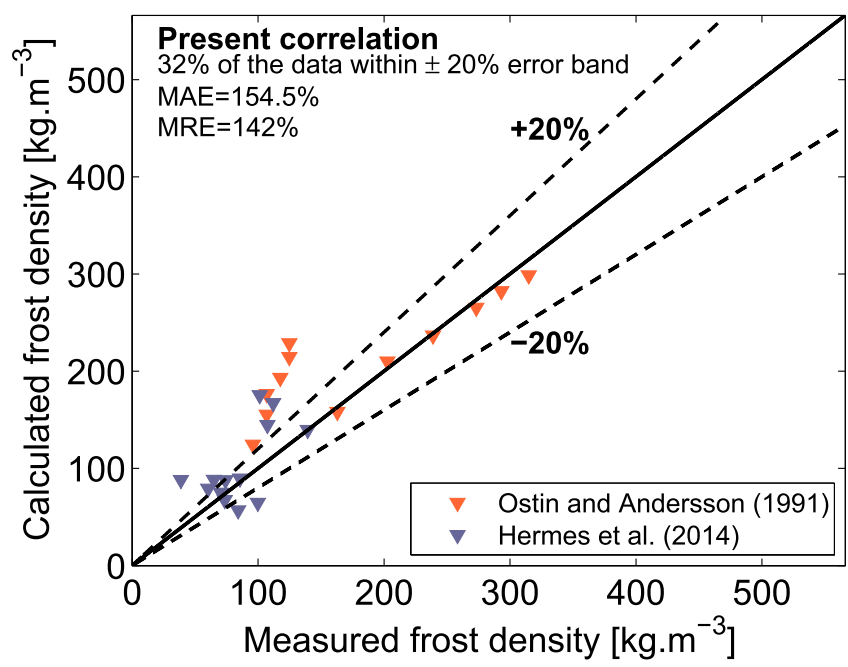

Fig. 23 - Correlation applied to parallel plate database. rameters, and quantitative and qualitative studies are presented. The impact of environmental parameters on frost thickness agrees for the three geometries: frost thickness increases with low wall temperature, high relative humidity and high velocity (this last impact was not verified for parallel plate configuration because of lack of data, but it can be considered that it would be identical). For frost density, as the number of data points is lower, conclusions are less strong. Frost density is found to increase with high wall temperature for single plates (horizontal and vertical) but authors cannot bring conclusions for parallel plates. The impact of relative humidity is only provided for vertical plate: high relative humidity causes a less dense frost layer. The impact of relative humidity on horizontal plate has to be clarified because conclusions available in literature are not in agreement. Concerning velocity, the impact is identical for all geometries: frost layer is denser with high velocity. For horizontal single flat plate, three of the five models presented for predicting frost thickness are satisfactory (Hermes, 2012; Hermes et al., 2009; Schneider, 1978). They can predict at least half of the database. However, predictive methods available for calculating frost density on single horizontal plate are not as efficient. Scattered results obtained drove authors of the present study to propose a new correlation which can predict more than $55 \%$ of the database. Several sources of discrep-

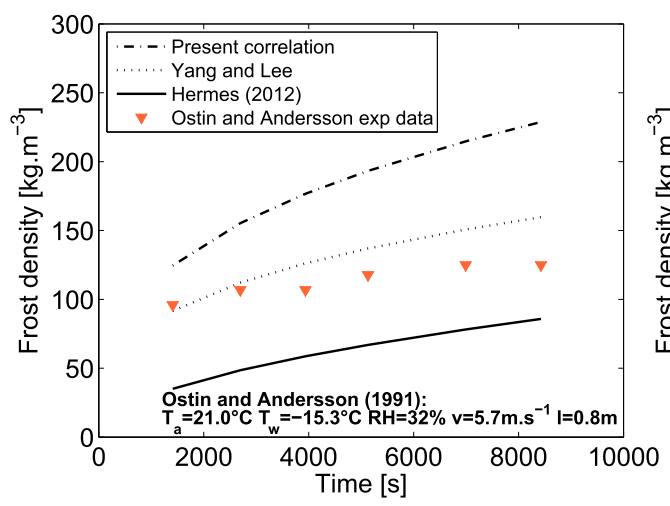

(a) High velocity

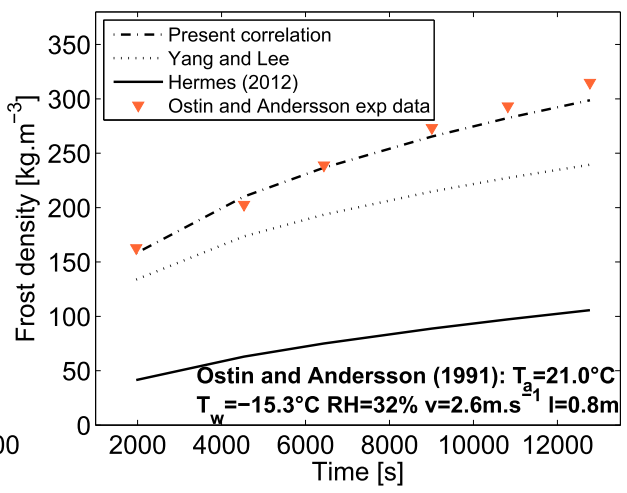

(b) Low velocity

Fig. 24 - Qualitative comparison for frost density: air velocity case. 
ancy between measurements and correlations have been proposed. A qualitative study showed that frost thickness is better predicted by low wall temperature, high relative humidity and high velocity. Opposite observations were made for frost density: scattering is lower with low wall temperature and high velocity. This study was extended to more realistic geometries: single vertical flat plate and parallel horizontal plates. Best predictive methods found in the first part were applied to the two databases for both thickness and density prediction. Models for frost thickness applied to vertical plate were found to not be adapted probably because of gravity effect. Frost density results were more convenient but still need to be improved. Gravity effect is probably affecting more thickness than density. For parallel horizontal plates, models were found to be more adapted albeit less efficient than for flat plate. This could be explained by the influence of both thermal and dynamic boundary layers on top of one another. To conclude, additional tests for all geometries are required. For single horizontal plate, authors should concentrate on relative humidity impact. For vertical and parallel plates, all kinds of data points are required. The present authors insist on the importance of providing all details that are necessary to be used in models. This study will later be completed with the building of an experimental bench.

\section{Acknowledgments}

This article has been realized in the framework of CIFRE convention. We would like to thank ANRT for its contribution.

\section{R E F E R E N C E S}

Breque, F., Nemer, M., 2015. Flat-tube exchanger modeling under frosting conditions for an electric vehicle heat pump. In: Proceedings of the International Congress of Refrigeration. pp. 393-420.

Cai, L., Wang, R., Hou, P., Zhang, X., 2011. Study on restraining frost growth at initial stage by hydrophobic coating and hygroscopic coating. Energy Build. 43 (5), 1159-1163.

Cheng, C.-H., Cheng, Y.-C., 2001. Theoretical model for prediction frost growth on a cold plate in atmospheric air. In: The 8th National Computational Fluid Dynamics Conference, E-Land.

Da Silva, D.L., Hermes, C.J., Melo, C., 2011. Experimental study of frost accumulation on fan-supplied tube-fin evaporators. Appl. Therm. Eng. 31 (6-7), 1013-1020.

El Cheikh, A., Jacobi, A., 2014. A mathematical model for frost growth and densification on flat surfaces. Int. J. Heat Mass Transf. 77, 604-611.

Fossa, M., Tanda, G., 2010. Frost formation in vertical channels under natural convection. Int. J. Multiphase Flow 36 (3), 210220.

Fukuta, N., 1968. Experimental studies on the growth of small ici crystals. J. Atmos. Sci. 26.

Hayashi, Y., Aoki, A., Hori, K., 1977. Study of frost properties correlating with frost formation types. J. Heat Transfer 99, 239-245.

Hermes, C.J., 2012. An analytical solution to the problem of frost growth and densification on flat surfaces. Int. J. Heat Mass Transf. 55 (23-24), 7346-7351.
Hermes, C.J., Piucco, R.O., Barbosa, J.R., Melo, C., 2009. A study of frost growth and densification on flat surfaces. Exp. Therm. Fluid Sci. 33 (2), 371-379.

Hermes, C.J., Loyola, F.R., Nascimento, V.S., 2014. A semiempirical correlation for the frost density. Int. J. Refrigeration 46, 100-104.

Hosoda, T., Uzuhashi, H., 1967. Effects of frost on the heat transfer coefficient. Hitashi Rev. 16, 254-259.

Iragorry, J., Tao, Y.X., Jia, S., 2004. Review article: a critical review of properties models for frost formation analysis. HVAC\&R Res 10 (4), 393-420.

Janssen, D., Mohs, W., Kulacki, F., 2012. High resolution imaging of frost melting. In: Proceedings of the ASME 2012 Summer Heat Transfer Conference.

Jones, B., Parker, J., 1975. Frost variation with varying environmental parameters. ASME J. Heat Transf. 97, 255-259.

Kandula, M., 2012. Frost growth and densification on a flat surface in laminar flow with variable humidity. Int. Commun. Heat Mass Transf. 39 (8), 1030-1034.

Le Gall, R., Griot, R.L., 1997. Modelling of frost growth and densification. Int. J. Heat Mass Transf. 40, 3177-3187.

Lee, K.-S., Kim, W.-S., Lee, T.-H., 1997. A one-dimensional model for frost formation on a cold surface. Int. J. Heat Mass Transf. 40, 4359-4365.

Lee, K.-S., Jhee, S., Yang, D.-K., 2003. Prediction of the frost formation on a cold flat surface. Int. J. Heat Mass Transf. 46 (20), 3789-3796.

Lee, Y.B., Ro, S.T., 2002. Frost formation on a vertical plate in simultaneously developing flow. Exp. Therm. Fluid Sci. 26 (8), 939-945.

Mao, Y., Besant, R., Rezkallah, K., 1992. Measurement and correlations of frost properties with airflow over a plate. ASHRAE Trans. 98, 65-77.

Mao, Y., Besant, R., Chen, H., 1999. Frost characteristics and heat transfer on a flat plate under freezer operating conditions: part i, experimentation and correlations. ASHRAE Trans. 105, 231-251.

Na, B., Webb, R.L., 2004. New model for frost growth rate. Int. J. Heat Mass Transf. 47, 925-936.

Nascimento, V.S., Loyola, F.R., Hermes, C.J., 2015. A study of frost build-up on parallel plate channels. Exp. Therm. Fluid Sci. 60, 328-336.

O'Neal, D., Tree, D., 1984. A review of frost formation on simple geometries. ASHRAE Trans. 91, 278-290.

Ostin, R., Andersson, S., 1991. Frost growth parameters in forced air stream. Int. J. Heat Mass Transf. 34.

Piucco, R.O., Hermes, C.J., Melo, C., Barbosa, J.R., 2008. A study of frost nucleation on flat surfaces. Exp. Therm. Fluid Sci. 32 (8), 1710-1715.

Sami, S., Duong, T., 1989. Mass and heat transfer during frost growth. ASHRAE Trans. 158-165.

Schneider, H.W., 1978. Equation of the growth rate of frost forming on cooled surfaces. Int. J. Heat Mass Transf. 21 (8), 1019-1024.

Seki, N., Fukusako, S., Matsuo, K., Uemura, S., 1985. An analysis of incipient frost formation. Wärme-und Stoffübertragung 19 (1), 9-18.

Storey, B., Jacobi, A., 1999. The effect of streamwise vortices on the frost growth rate in developing laminar channel flows. Int. J. Heat Mass Transf. 42.

Tao, Y., Besant, R., Rezkallah, K., 1993. A mathematical model for predicting the densification and growth of frost on a flat plate. Int. J. Heat Mass Transf. 36.

Wang, W., Guo, Q., Lu, W., Feng, Y., Na, W., 2012. A generalized simple model for predicting frost growth on cold flat plate. Int. J. Refrigeration 35 (2), 475-486. 
Wu, X., Dai, W., Xu, W., Tang, L., 2007. Mesoscale investigation of frost formation on a cold surface. Exp. Therm. Fluid Sci. 31 (8), 1043-1048.

Yamashita, K., Hamada, K., Ise, S., Ohkubo, H., 2007. Study of frost properties in a low temperature environment. In: Proceedings of the International Congress of Refrigeration. pp. 393-420.
Yang, D.-K., Lee, K.-S., 2004. Dimensionless correlations of frost properties on a cold plate. Int. J. Refrigeration 27 (1), 89-96.

Yonko, J.D., Sepsy, C.F., 1967. An investigation of the thermal conductivity of frost while forming on a flat horizontal plate. ASHRAE 74th Annual Meeting 2043. 